\title{
Written Exposure Therapy as Step One in Reducing the Burden of PTSD: The Composite Cases of "Alex," "Bruno," and "Charles"
}

\author{
DAVID J. AUSTERN ${ }^{\mathrm{a}, \mathrm{b}, \mathrm{c}}$ \\ ${ }^{\mathrm{a}}$ The Steven A. Cohen Military Family Clinic at NYU Langone Medical Center, New York, NY \\ ${ }^{\mathrm{b}}$ Correspondence regarding this article should be sent to David Austern, The Steven A. Cohen Military Family \\ Clinic, NYU Langone Medical Center, One Park Avenue, $8^{\text {th }}$ Floor, New York, NY 10016 \\ Email: david.austern@nyumc.org \\ ${ }^{\mathrm{C}}$ Note: This article is a reformatted and edited version of my dissertation (Austern, 2015)
}

\begin{abstract}
The purpose of this study is to explore the effects of a stepped-care model of treatment on Posttraumatic Stress Disorder (PTSD) symptomatology and sequelae in United States' Veterans. The study provides a literature review of the burden of PTSD, describes current best treatment practices, and illustrates key processes in the service-delivery of these treatments. Treatment considerations are demonstrated via three hybrid case examples, which serve as vivid portrayals of Veteran clients who struggle with research-consistent PTSD symptomatology and difficulties engaging in psychotherapy. In addition to being informed by clinical examples in relevant psychological literature, these composite cases, “Alex," "Bruno," and "Charles," contain disguised aspects drawn from psychotherapy clients who have been in my caseload in a PTSD clinic. Demonstrating these clients' courses of treatment provides an avenue for describing key clinical issues related to Veteran engagement in evidence-based PTSD therapy. By adopting a qualitative, disciplined inquiry approach, treatment is tailored to the client's unique psychological struggles within the context of historical, contextual, and cultural factors. Using a pragmatic case study research format (Fishman, 2013), case material is analyzed both qualitatively and quantitatively. The cases illustrate how a stepped-care model of treatment, beginning with Written Exposure Therapy (WET; Sloan, Lee, Litwack, Sawyer, \& Marx, 2013) and culminating in Prolonged Exposure Therapy (PE; Foa, Hembree, \& Rothbaum, 2007), has the potential to be distinctively helpful in the treatment of Veterans suffering from PTSD. These case studies are designed to be a resource for therapists who seek to gain additional understanding of how to provide efficient and effective treatment to Veterans.
\end{abstract}

Key words: PTSD; military combat; veterans; trauma; exposure therapy; Prolonged Exposure (PE); Written Exposure Therapy (WET); writing; stepped-care; composite case studies; clinical case studies

\section{CASE CONTEXT AND METHOD}

\section{The Rationale for Selecting These Particular Clients for Study}

In a recent op-ed piece run by The New York Times, a United States Marine Corps Veteran discussed his negative experiences receiving psychotherapy for Posttraumatic Stress 
Disorder (Morris, 2015). Titling his article “After PTSD, More Trauma,” the author criticized the Veterans Affairs Healthcare System for its "unforgivably long wait times," its "erratic quality of care,” and the "overhyped therapy” (i.e., Prolonged Exposure Therapy) offered to him by graduate-student clinicians at his local VA. The author reported that he dropped out of Prolonged Exposure therapy prematurely, analogizing it to "emotional chemo (therapy)" and cautioned the public against its effectiveness. Although this author represents one unique data point, his article highlights the growing public health concern that Veterans suffering from PTSD are dissatisfied with their treatment or are not receiving treatment at all.

It has been suggested that psychotherapy research and practice needs to better address the growing burden of mental illness (Kazdin \& Blase, 2011). These authors note that there is a tremendous discrepancy between the supply and demand for mental health services, which, according to them, traditional one-on-one psychotherapy is ill-equipped to handle. Posttraumatic stress disorder is an example of a disorder where the demand for mental health services greatly exceeds the supply. Schell and Marshall (2008) surveyed nearly 2,000 Operation Iraqi Freedom and Operation Enduring Freedom Veterans and found that only half who met criteria for PTSD had received treatment over the previous year, with only $1 / 4$ receiving minimally adequate treatment. To combat this problem, Kazdin and Blase (2011) reconsider conventional wisdom that the best interventions have the largest effect sizes and instead argue for having a portfolio of interventions, which could include interventions with moderate effect sizes as long as they target a different population or serve a different purpose.

In an invited response, Sloan, Marx, and Keane (2011) discussed how the United States Department of Veterans Affairs has attempted to accomplish this by incorporating technological innovations into their evidence-based mental health treatments for posttraumatic stress disorder, which has increased their ability to disseminate these treatments. These authors concede that the VA's two evidence-based treatments, Cognitive Processing Therapy (CPT; e.g., Resick, Monson, \& Rizvi, 2008) and Prolonged Exposure Therapy (PE; e.g., Foa, Hembree, \& Rothbaum, 2007), are efficacious. However these treatments have not eradicated PTSD entirely due to people being unable to access the treatments, people dropping out of treatment prematurely, and even people being treatment non-responders after receiving them. Data suggests that approximately $1 / 4$ of people in exposure-based PTSD treatments drop out (Hembree et al., 2003) and 1/3 of treatment completers continue to meet diagnostic criteria for PTSD (Bradley, Greene, Russ, Dutra, \& Westen, 2005). As such, the VA system is still working toward developing new interventions and has recently created a promising intervention involving writing (i.e., Sloan, Marx, Bovin, Feinstein, \& Gallagher, 2012)—Written Exposure Therapy (WET). Because there is evidence that the exposure component of PTSD treatments is necessary for clinically significant symptom change (Foa, 2009), this new treatment was designed with a written exposure component. Based on promising pilot study data, WET has been discussed as a possible initial option in a stepped care model for treating PTSD.

During my clinical training, I have treated many Veterans who were struggling with PTSD and have observed a variety of treatment courses and responses to treatment. Unfortunately, some of them have either prematurely dropped out of evidence-based treatments such as Prolonged Exposure and Cognitive Processing Therapy or refused to even try them and 
opted for a nonspecific, supportive treatment. However, other Veterans have been willing to attempt these treatments and have experienced a reduction in PTSD symptoms. For many of these Veterans, brief writing interventions have been a preferable alternative to or initial offering prior to beginning Prolonged Exposure and Cognitive Processing Therapy.

In order to explore the effects of receiving a stepped-care model of PTSD treatment beginning with Written Exposure Therapy and culminating in Prolonged Exposure, I have created three hybrid case examples_labeled "Alex," "Bruno," and "Charles"—which is an extension of a pragmatic case study (Fishman, 2013). In addition to being informed by clinical examples in relevant psychological literature, these composite cases are assembled from actual psychotherapy cases I have treated during my clinical training. The hybridized cases will serve as vivid portrayals of Veteran clients who struggle with research-consistent PTSD symptomatology and difficulties engaging. Presenting three courses of treatment with these clients provides an avenue for describing key clinical issues related to Veteran engagement in evidence-based PTSD treatments. Additionally, by demonstrating my first-hand clinical experiences, these case studies will build upon the existing knowledge base of best treatment practices that are currently found within the psychological literature. Since no single case can illustrate the heterogeneity of experiences for the Veteran population, these hybrid cases should not be interpreted as the only presentation of Veteran clients with PTSD. However, by highlighting common themes that emerged in my psychotherapy treatment experiences, I hope to increase therapists' understanding of clinical issues likely to arise, assist clinicians in their ability to formulate case conceptualizations for their Veteran clients, and improve the quality and effectiveness of psychotherapy services for this population.

The dissertation's structure follows the format of a PCSP-structured pragmatic case study, which includes: (i) detailed description of the hybridized clients; (ii) assessment of the clients' presenting problems, goals, strengths, and history; (iii) the theoretical guiding conception and literature review; (iv) case formulation and treatment plan; (v) course of treatment; (vi) therapy monitoring and use of feedback; and (vii) a final quantitative and qualitative analysis of the therapy outcome (Fishman, 2013). I review literature on the evidence-based treatments currently available, the novel treatments being currently studied, and describe what are currently thought of as the best treatment practices when working with Veterans suffering from PTSD. I adopt a qualitative, disciplined inquiry approach (Peterson, 1996), which allows treatment to be tailored to the client's unique psychological struggles within the context of historical, contextual, and cultural factors. As therapy progresses, reassessments allow for necessary "shifts” in focus according to the hybridized client' mental health needs. I provide the reader with the results of fictionalized quantitative measures in order to concretely demonstrate the clients' levels of PTSD and depression. This study's data reflects general patterns I have observed within data I have collected across treatment with my PTSD clients.

In this study I present three composite cases of Veteran clients, ages 27 through 69, for whom I have provided PTSD treatment in outpatient settings over my years as a doctoral-level graduate student. The composite clinical cases in this study, hereafter referred to by the pseudonyms “Alex," "Bruno," and "Charles," are a heterogeneous group of Veterans presenting with symptoms of PTSD and associated difficulties. These Veterans are at quite different stages 
of life, but share the common experience of seeking to overcome their traumatic pasts.

\section{The Clinical Setting in Which the Cases Took Place}

Alex, Bruno, and Charles' treatment took place at a small specialty training clinic for Anxiety and Related Disorders in the Northeastern United States. This clinic houses a mental health program that allows eligible Veterans to receive free psychotherapy by graduate-student clinicians in training as well as licensed clinical psychologists. The program is in partnership with the state's Veterans Affairs Healthcare System and offers Veterans an alternative to receiving treatment at the main VA hospital. At the time Alex, Bruno, and Charles were referred, the clinic was offering stepped-care treatment to all prospective Veteran clients suffering from PTSD. Throughout my treatment with these Veterans, I was supervised by a licensed clinical psychologist with knowledge of cognitive-behavioral treatments for PTSD. Their treatments lasted for 7, 16, and 9 weekly sessions, respectively.

\section{Sources of Data Available Concerning the Client}

No information was available to me prior to beginning treatment with Alex, Bruno, and Charles other than brief demographic data regarding their eligibility to be seen through our program, which was faxed over prior to their initial sessions. Two of the three Veterans had prior experience with psychotherapy and collateral information (e.g., from family members or health care providers) was not acquired.

\section{Confidentiality}

Given that Alex, Bruno, and Charles are not real people, but are composites of multiple individuals, the confidentiality of my previous clients will be protected. Additionally, in order to further protect my clients' identities, details of the hybridized cases have also been fictionalized.

\section{THE CLIENTS}

“Alex,” a 27-year-old, male, married, Caucasian, Operation New Dawn, 30\% Service Connected for a knee injury, Army Veteran, sought treatment in order to address difficulties with intrusive memories, avoidance, self-blame, concentration issues, and "jumpiness" in the presence of loud noises. His index trauma was an Improvised Explosive Device (IED) blast that wounded him and killed some of his friends during a convoy mission. He presented with symptoms of and met criteria for Posttraumatic Stress Disorder (PTSD), as defined by the American Psychiatric Association's (2013) Diagnostic and Statistical Manual of Mental Disorders, Fifth Edition (DSM-5), including intrusions, avoidance, negative alterations in cognitions and mood, and alterations in arousal and reactivity. He also reported experiencing chronic pain, which reportedly exacerbated his PTSD symptoms. Additionally, Alex expressed that he was having marital conflict due to his PTSD symptoms and acknowledged that his wife referred him to the clinic; this was Alex's first experience with individual therapy. Our treatment spanned seven sessions over the course of approximately two months. 
Bruno,” a 48-year old, male, divorced, Hispanic, Persian Gulf-era, non-Service Connected Navy Veteran sought treatment in order to address difficulties with "freaking out" when reminded of traumas, self-blame, persistent shame, "constant scanning," and frequent anger. His index trauma was Military Sexual Trauma (MST). He presented with symptoms of and met criteria for Posttraumatic Stress Disorder (PTSD), as defined by the American Psychiatric Association's (2013) Diagnostic and Statistical Manual of Mental Disorders, Fifth Edition (DSM-5), including intrusions, avoidance, negative alterations in cognitions and mood, and alterations in arousal and reactivity. He also met criteria for Alcohol Use Disorder in early remission in a controlled environment. At his children's request, Bruno had been living in a community halfway house for substance use recovery where his case manager recommended he seek treatment for PTSD. Approximately fifteen years earlier, he had seen a psychoanalyst in the community for several sessions before discontinuing treatment; otherwise, this was his first experience with individual therapy related to the trauma. Our treatment spanned sixteen sessions over the course of approximately four months.

“Charles,” a 69 year-old, male, widowed, Black, Vietnam, 50\% Service Connected for PTSD, United States Marine Corps Veteran sought treatment in order to address difficulties with nightmares, "alienation from society," and "self-destructive behavior.” His index trauma was witnessing his best friend commit suicide by gunshot wound to the head. He presented with symptoms of and met criteria for Posttraumatic Stress Disorder (PTSD), as defined by the American Psychiatric Association’s (2013) Diagnostic and Statistical Manual of Mental Disorders, Fifth Edition (DSM-5), including intrusions, avoidance, negative alterations in cognitions and mood, and alterations in arousal and reactivity. Since returning from Vietnam, Charles received multiple courses of supportive psychotherapy at his local VA hospital and community Vet Center. His Vet Center therapist recently retired, at which time he was referred for treatment to this clinic. Our treatment spanned ten sessions over the course of approximately three months.

\section{GUIDING CONCEPTION WITH RESEARCH AND CLINICAL EXPERIENCE SUPPORT}

\section{The Burden of PTSD}

Posttraumatic Stress Disorder (PTSD) is a syndrome that occurs after someone directly experiences, witnesses, or learns about a traumatic event, where they develop intrusions about the event, avoid reminders of the event, have negative alterations in their thoughts and feelings in relation to the event, and have negative alterations in their arousal system in relation to the event. Kessler (2000) found that PTSD is highly prevalent and impairing, with an estimated annual productivity loss of approximately $\$ 3$ billion. Recently, the RAND Corporation published a seminal study on the post-deployment health-related needs associated with PTSD, Major Depression, and Traumatic Brain Injury among OEF/OIF veterans, as well as the economic costs and systemic issues associated with providing health care to reduce the burden of the aforementioned conditions (Tanelian \& Jaycox, 2008). The authors found that Veterans with PTSD tend to miss more days of work, report being less productive while at work, are more likely to be unemployed, are more likely to be homeless, experience marital disruptions, 
interference with parenting, and may indirectly lead to problems in their children. Using a stateof-the-art microsimulation model, the authors predicted that that two-year costs resulting from PTSD and major depression for the approximately 1.6 million individuals who have deployed since 2001 could range from $\$ 4.0$ to $\$ 6.2$ billion. For an individual Veteran with PTSD, unique costs over those two years ranged from $\$ 5,904$ to $\$ 10,298$.

To combat this problem, the authors estimated that providing evidence-based treatment to these Veterans would likely temporarily increase costs but ultimately cut costs nearly by $1 / 3$ in the long-term. Based on these findings, the authors recommended that Veterans should be empowered to seek evidence-based treatments and the Department of Defense and Veterans Affairs Healthcare System should attempt to increase their capacity to deliver these treatments. Tuerk et al. (2013) examined health-service utilization among Veterans who received Prolonged Exposure within a VA PTSD specialty clinic and found that, contrary to their hypotheses, Veterans who dropped out of PE continued to use mental health services at a significantly higher rate than those Veterans who completed PE. This finding underscores the economic cost of Veterans not receiving EBPs for PTSD, as the authors estimated the clinic saved \$11,644 due to offering PE to the Veterans enrolled in the study.

\section{VA/DoD PTSD Practice Guidelines}

The development of the PTSD practice guidelines (VA/DoD, 2010) arose from the growing need to diagnose and treat Post-Traumatic Stress among the military and Veteran population. The most recent update to these practice guidelines, the 2013 pocket guide, describes the critical decision points when managing Post-Traumatic Stress Disorder and Acute Stress Reaction based on DSM-IV criteria; they have not yet been updated to include DSM 5 criteria. They are intended to provide clear and comprehensive evidence-based recommendations incorporating current information and best practices for practitioners throughout the Department of Defense and Veterans Affairs Health Care systems. Level A psychotherapy interventions for PTSD, which are strongly recommended based on data suggesting they are likely to provide significant benefit, are Trauma-focused psychotherapy that includes components of exposure and/ or cognitive restructuring, as well as Stress inoculation training. Prolonged Exposure and Written Exposure are both included among the exposure- based Level A psychotherapy interventions.

\section{Prolonged Exposure}

Prolonged Exposure (PE; Foa, Hembree, \& Rothbaum, 2007) is an 8 to 15 session treatment for PTSD that includes four components in the following order: education-rationale, breathing retraining, behavioral exposures, and imaginal exposures. During the first session, clients are educated about the symptoms of PTSD and the therapist provides a rationale for in vivo and imaginal exposure in the context of avoidance reduction and habituation of conditioned negative emotional responses. Clients are also introduced to breathing retraining. In Session 2, rationale and education continue, subjective units of distress ratings are introduced, the therapist and client generate an in vivo exposure hierarchy, and the first in vivo exposure assignment is given. 
Sessions 3 to 9 begin by reviewing homework assignments, conducting imaginal exposure for 45-60 min of the 90-min session (depending on the length of the incident and the number of repetitions possible), and processing the exposure experience with nondirective statements (e.g., education about trauma reactions, paraphrasing, reiterating the treatment rationale, and normalizing reactions). After several sessions of conducting an imaginal exposure of the complete memory, the focus of the imaginal exposure shifts to the most distressing aspect of the memory (i.e. the "hot spot"). Throughout the treatment, clients are instructed to listen to the tape of the imaginal exposure sessions each day and to engage in behavioral exposures with increasing difficulty for at least 45 min per day.

I selected Prolonged Exposure to be the second treatment offered within the stepped-care model over Cognitive Processing Therapy (CPT; Resick \& Schnicke, 1992; Resick, Monson, \& Rizvi, 2008), which is another evidence-based treatment for PTSD, for several reasons. For starters, I wanted to keep the mechanism of action in the treatments as consistent as possible; Written Exposure Therapy and Prolonged Exposure are both exposure-based treatments, whereas CPT, especially the more cognitive version of CPT-C, relies on cognitive therapy as its key ingredient. Furthermore, standard CPT also includes a written component, where the Veteran client writes a detailed written account of the index trauma (Resick \& Schnicke, 1992), which I thought would be repetitive after someone completed WET. There remains a need to empirically study whether PE and CPT work equally well as the intensive treatment (i.e., step two) in stepped-care models for treating PTSD.

\section{The Tolerability of Psychotherapies for PTSD}

Although there are many studies documenting Prolonged Exposure's effectiveness in treating PTSD, there is an ongoing debate as to how well-tolerated the treatment is. A recent meta-analysis (Imel, Laska, Jakupcak, \& Simpson, 2013) examined dropout rates in PTSD treatments and found that, on average, $18 \%$ of clients dropped out of active treatment in clinical trials for PTSD. However, these authors noted that there was substantial variability across studies depending on the type of treatment used and the dropout rates for exposure-based treatments ranged as high as $41 \%$ (e.g. McDonagh et al., 2005). Ultimately, these authors declared that all trauma-focused treatments do not significantly differ in terms of predicting dropout and thus recommended that clinicians should not avoid using a trauma-focused treatment based on fear of their client dropping out. Furthermore, the authors conclude that an 18\% dropout rate within randomized clinical trials would be a huge improvement over the dropout rates found in real-world studies of treatment utilization.

Within the Veterans Affairs Healthcare System, PTSD treatment often occurs inside a specialty clinic known as the PTSD Clinical Team (PCT). Several recent studies have examined outcomes from exposure-based therapies for PTSD within PCTs throughout the VA. In a retrospective chart review study, Mott et al. (2013) found that Iraq and Afghanistan Veteran status as well as a history of psychiatric inpatient hospitalizations were associated with dropping out of Evidence Based Psychotherapy (i.e. Prolonged Exposure and Cognitive Processing Therapy). 
Yoder et al. (2012) compared outcomes in combat Veterans across theaters (i.e., Vietnam, Persian Gulf, OEF/OIF/OND) and found all groups to benefit from Prolonged Exposure (i.e. overall effect size of 2.73 across the three groups). However, they also found that the groups significantly differed in their dropout rates, with Returning Veterans being most likely to not complete the treatment (26\% dropout), Persian Gulf Veterans dropping out at $12 \%$, and Vietnam Veterans being most likely to complete the treatment (3\% dropout). These authors speculated that their relatively low overall dropout rates may have been due to the fact that the majority of Veterans in their study completed a mandatory 3-4 session orientation class, which was designed to provide them with psychoeducation about PTSD symptoms and treatment options and may have influenced their treatment engagement. Although this would not necessarily be considered a stepped-care model of PTSD treatment due to the orientation class not being designed as a treatment itself, it nonetheless highlights the idea that it may be helpful to provide Veterans with resources prior to engaging them in individual trauma-focused treatments like Prolonged Exposure.

Another recent study using a PCT sample (Jeffreys et al., 2014) found that Veterans who received Prolonged Exposure were more likely to benefit (i.e. effect size of 2.01) than those Veterans who received Cognitive Processing Therapy (i.e. effect size of .96). However, the dropout rate for Prolonged Exposure was higher (44.4\%) than the dropout rate for Cognitive Processing Therapy (32.2\%). Among those Veterans who received Prolonged Exposure, after adjusting for covariates, age predicted the odds of dropping out, where Veterans under 30 were more likely to dropout than Veterans over 50 . The authors concluded that it is not necessarily OEF/OIF/OND status that predicts higher dropout, but rather the Veterans' ages, which may be associated with competing life responsibilities that inhibit treatment engagement.

Schottenbauer, Glass, Arnkoff and Gray (2008) argued that research on alternative approaches to PTSD treatment was needed based on the large nonresponse and dropout rates found in treatment studies using Prolonged Exposure and Cognitive Processing Therapy. As such, researchers have developed novel treatments for PTSD using a variety of technologies. For example, exposure-based treatments have begun including virtual reality technology to simulate different environments (e.g. World Trade Center) where traumas may take place (Difede et al., 2007). Additionally, in recent studies, novel pharmacotherapeutics (e.g. D-Cycloserine) have been used to augment the extinction learning process that may occur during exposure therapy (Difede et al., 2014). Finally, writing-based interventions have been developed into PTSD treatments, although writing about traumatic events has been studied for decades.

\section{Writing About Trauma}

Since the mid-1980s, research has indicated that writing about traumas or emotional upheavals in our lives can improve our physical and mental health (Pennebaker, 2010). In these studies, known as the Expressive Writing paradigm (e.g. Pennebaker, Kiecolt-Glaser, \& Glaser, 1988), participants are randomly assigned to write about traumas/emotional upheavals or to write about superficial topics. When participants write about traumas/emotional upheavals they tend to receive health benefits relative to participants who write about trivial topics. Researchers have attempted to generate answers to the questions of who expressive writing works best for, when it 
works best, what dosage leads to the best effects, how well it works, and why it works (Pennebaker, 2010). Perhaps unsurprisingly, some of these questions currently remain unanswered due to inconclusive results and the boundary conditions of expressive writing are somewhat undefined (Pennebaker \& Chung, 2011). Nonetheless, expressive writing has been incorporated into a variety of clinical interventions based on its therapeutic potential.

Over the past few years, the aforementioned VA researchers have been studying writing by examining the efficacy of Pennebaker's expressive writing paradigm for a PTSD sample (Sloan, Marx, \& Greenberg, 2011). The authors raised concerns of whether expressive writing only works for healthy populations and they tested that hypothesis, initially finding no significant differences in PTSD symptom reduction between the experimental and control conditions, although both groups exhibited PTSD symptom reduction. They also initially found that habituation (i.e. one of the hypothesized mechanisms of exposure therapy) did not occur, which led them to speculate that habituation requires more time than three writing sessions to occur (Sloan, Marx, \& Greenberg, 2011). Written Exposure Therapy (Sloan et al., 2012) was created to test this hypothesis (i.e. upping the dosage of written exposure will allow habituation to occur in PTSD samples), as well as test the hypothesis that the treatment would be a more tolerable alternative to CPT and PE (i.e. dropout rate would be lower for WET).

\section{Written Exposure Therapy (WET)}

Written Exposure Therapy (Sloan \& Marx, personal communication) is a brief (i.e., 5 sessions), writing-based treatment that includes two components in the following order: education-rationale and written exposures. During the first session, clients are educated about the symptoms of PTSD and the therapist provides a rationale for written exposure in the context of avoidance reduction and habituation of conditioned negative emotional responses. The therapist then gives general directions for written exposures and gives specific instructions for session 1 . This direct therapist contact is designed to take approximately 25 minutes. Afterward, the therapist leaves a hard copy of the instructions with the client while they complete their writing alone for 30 minutes, reminding them that the trauma is being recounted, not relived.

The therapist then returns to the room and inquires whether the client experiences any difficulties during the writing session and addresses any problem or concerns that may arise. The therapist also checks the written narrative to make sure that the instructions are followed. The session ends with the therapist instructing the client to allow him/her-self to experience any trauma- related memories, images, thoughts or feelings, whatever they might be, in the week between sessions. This instruction is provided to reiterate the importance of confronting trauma memory, rather than engaging in avoidance, a theme that is emphasized during the treatment rationale portion of the protocol. No other explicit between-session homework is assigned to clients. This direct therapist contact is designed to take approximately 5 minutes. In sessions 25 , clients are instructed to focus on providing a detailed description of the part of the event that is most distressing to them ("hot spot"), as well as to describe how the event has affected their lives (e.g., how the event changed the way the person interacts with others, how the event has changed the way in which the person views his/her life). The instruction to write about the traumatic event from a distance perspective is included based on research indicating that taking a distance 
perspective allows individuals to better engage in trauma recounting (e.g., Kross \& Ayduk, 2011).

Because the therapy consists of five sessions of writing about the trauma with minimal therapist contact, this makes it easily disseminated (Sloan et al., 2012). Furthermore, the authors argued that the potential exists for this treatment to be administered without extensive training and experience treating trauma survivors, although they acknowledged that additional research on the efficacy of WET with novice clinicians is needed. Their initial study was a randomized clinical trial using a motor-vehicle accident trauma sample, and the authors found that WET achieved an effect size of 3.49 (i.e., habituation did occur) at post relative to waitlist controls and they only had a $9 \%$ dropout rate (i.e., the treatment was well-tolerated). Although this data was extremely promising, it remained unclear how the therapy would be received by Veterans.

As a follow-up study, the treatment was pilot tested in an uncontrolled trial with a small Veteran PTSD sample (Sloan, Lee, Litwack, Sawyer, \& Marx, 2013). Of the seven Veterans who began the study, six completed the treatment and the one Veteran who dropped out (14\%) nonetheless returned to complete follow-up assessments. Of note, the study included qualitative data related to this particular Veteran's rationale for dropping out; after receiving three sessions of WET, he reportedly declined to continue because he did not believe the treatment would benefit him. However, all Veterans appeared to benefit from the treatment and showed increasing symptom improvement over time, where four of the seven participants had reductions in PTSD symptom severity at posttreatment, and six of seven displayed clinically significant improvements at three month follow-up; five of the seven participants no longer met diagnostic criteria for PTSD both at posttreatment and follow-up. Based on these findings, the authors speculated that WET could work well as the initial option in a stepped care model of PTSD treatment, where WET would be offered to Veterans and then they would have the option of "stepping up" to a more intensive treatment. Additionally, WET is currently being compared against CPT in a noninferiority, randomized clinical trial (Sloan, Marx, \& Resick, 2016).

\section{Stepped Care}

Stepped-care is a method of service delivery which offers people the "least restrictive" treatment that is expected to offer them some benefit initially, with the option to "step them up" to a more intensive treatment if they are not benefitting (Bower \& Gilbody, 2005). Thus, stepped-care aims to maximize available therapeutic resources by reserving the most costly treatments (i.e., direct therapist contact hours, therapist training required) for the people who require those (Bower \& Gilbody, 2005). In Bower and Gilbody's literature review on steppedcare models of psychological therapies (2005), they outline three assumptions underlying the construction of a strong stepped-care model of treatment-the equivalence assumption (i.e., a brief intervention is equally effective as existing treatments); the efficiency assumption (i.e., an equivalent treatment is more cost-effective than existing treatments due to its reduced therapist involvement); and the acceptability assumption (i.e., clients view the brief intervention as acceptable). 
Written Exposure Therapy would appear to meet the efficiency assumption due to its probable cost-effectiveness as compared to Prolonged Exposure or Cognitive Processing Therapy, where WET requires 75 total minutes of face-to-face therapist contact versus more than 500 total minutes of face-to-face therapist contact in PE and CPT. The available data would also suggest that Written Exposure Therapy meets the acceptability assumption based on its low dropout rates and perceived treatment credibility and client satisfaction (Sloan et al., 2012). Until the noninferiority trial data is published, it will remain unclear whether Written Exposure Therapy meets the equivalence assumption because we won't know whether it is equally effective as Cognitive Processing Therapy, which is presumed to be equally effective as Prolonged Exposure (Resick, Nishith, Weaver, Astin, \& Feuer, 2002).

Due to the overall lack of research on stepped-care, Bower and Gilbody (2005) conclude that the optimal configuration of stepped-care models remains unclear, as these three assumptions are often in tension with one another. Furthermore, there is controversy over the decision-making processes the therapist and client undertake regarding whether to step the client up to a more intensive level of care. As the authors note, there is often a tradeoff between complex, client-centered decision-making and algorithm-based decision-making that can be more cost-effective. While stepped-care models have been used to treat a variety of psychological disorders (e.g., eating disorders, depression), there have been few studies on how stepped-care service delivery may benefit those suffering from PTSD and even fewer including Veteran samples.

The VA/DoD practice guidelines advocate a pharmacotherapy-based stepped-care model of treating PTSD. This model begins with initial treatment consisting of SSRI or SNRI medication or psychotherapy for 4-6 weeks with reassessment occurring 2-4 weeks after initial treatment is initiated. At Step 1, adherence to treatment recommendations is assessed and addressed, medication dosage is possibly increased, and there is the option to switch to another SSRI/SNRI and/or add psychotherapy. At Step 2, which occurs 8-12 weeks after initial treatment is initiated, psychotherapy is added and/or medication is switched to mirtazapine. At Step 3, which occurs at least 12 weeks after initial treatment is initiated, there are additional medication switches available as well as the addition of psychotherapy. Throughout this model, a prescriber is encouraged to add prazosin at any time for sleep/nightmare disturbance. Although this model does feature a combination of pharmacotherapy and psychotherapy, it presumes that Veterans are willing to engage in both forms of treatment.

A recent pilot study examined how CBT treatments for PTSD can be adapted to serve active-duty military within an integrated primary care clinic (Cigrang et al., 2011). The researchers created a treatment protocol designed to combine elements from CPT and PE that could be delivered in four to six 30 minute sessions by psychologists serving as behavioral health consultants. Notably, this protocol had the participants write about their trauma initially, although the follow up sessions involved more active therapist involvement in facilitating emotional processing than in WET. Another noteworthy aspect of this protocol is that it was strictly nonpharmacological, as some studies (Tanielian \& Jaycox, 2008) suggest the greatest barrier to seeking care for military members is concern over medication's possible side effects. 
Cigrang and colleagues (2011) found significant reductions in PTSD severity, depression, and global mental health functioning for Operation Iraqi Freedom and Operation Enduring Freedom veterans. Although half of treatment completers no longer met criteria for PTSD, 33\% of the intent to treat sample prematurely dropped out of treatment. Nonetheless, the authors conclude that their brief intervention could be integrated into a primary care setting as the first step in a model that culminates in a referral to a specialty clinic for a more intensive treatment.

\section{What is Patient-Centered Care for PTSD?}

Although evidence-based treatments such as Prolonged Exposure and Cognitive Processing Therapy work well when Veterans receive and complete them, researchers have attempted to improve the service-delivery of these treatments to combat dropout as well as identify alternative service-delivery models (e.g., stepped-care, novel treatments, offering treatments in primary care settings) that may reduce the burden of PTSD by increasing provider capacity. The assumption is that these efforts will result in care that is more patient-centered for Veterans. According to the Institute of Medicine (2001), patient-centered care means respecting individual client preferences and characteristics, with client values primarily guiding clinical decisions and clients being in control of their own care. One of the Institute of Medicine's recommendations was to encourage shared clinical decision-making between provider and client, which was theorized as a radical shift from previous norms of healthcare professionals exercising control.

Shared decision-making (Barry \& Edgman-Levitan, 2012) is recommended when there are multiple viable treatment options, as is often the case. These authors recommend the use of decision aids, which offer clients psychoeducation to inform them about treatment options and help them communicate their own preferences to the provider. Recently, researchers have investigated whether shared decision-making increases the likelihood of Veterans selecting evidence-based treatments for PTSD over usual care approaches to treatment planning (Mott, Stanley, Street, Grady, \& Teng, 2014). Although this study employed a small Veteran sample (i.e. $n=20$ ), the authors found striking differences in treatment preferences between the two study conditions, where no Veterans assigned to usual care opted to begin an evidence-based psychotherapy for PTSD (e.g. Prolonged Exposure or Cognitive Processing Therapy) but six Veterans assigned to the shared decision-making intervention opted to begin an EBP (5 for CPT, 1 for PE). However, we must remember that only 6 of 20 Veterans preferred an EBP, with the overwhelming majority opting for other treatments such as psychoeducational groups and supportive treatments.

What is a provider to do when a Veteran presenting with PTSD communicates a preference for supportive therapy or a psychoeducational group? Unfortunately, these treatments are not likely to improve PTSD symptoms, as they are often used as the control intervention in effectiveness studies. For example, Neuner, Schauer, Klaschik, Karunakara, and Elbert (2004) offered Sudanese refugees with PTSD Narrative Exposure Therapy (i.e., another writing-based PTSD treatment), Supportive Counseling, or Psychoeducation and found that 29, 79, and 80, respectively, of the participants met criteria at one year post-treatment follow-up. $77 \%$ of the Supportive Counseling participants and 91\% of the Psychoeducation participants were classified 
as "severe mental health cases" at that time point. Thus, the people who opted to receive supportive counseling or psychoeducation over a trauma-focused treatment were significantly less likely to achieve PTSD symptom remission. Although a VA PTSD Clinical Team (PCT) may want to provide ongoing support/coping for EBP nonresponders or dropouts, the clinic and Veterans will likely benefit from allocating most staff resources to providing EBPs like Prolonged Exposure because they will increase capacity which will result in more Veterans being treated (Tuerk et al., 2013). It would seem that the more clients seen would offer more opportunities to provide patient-centered care.

In a recent nationwide survey (Hamblen et al., 2015), PTSD Clinical Team clinic directors reported on each of their clinic's efforts to implement EBPs; while the general consensus was that PCTs are enthusiastic about EBPs, there are some noteworthy barriers. One finding was that Returning Veterans were more likely to be offered Prolonged Exposure or Cognitive Processing Therapy than Veterans of other eras. This dovetailed with longstanding Veteran clients' perceived barriers to engaging in EBPs, which included skepticism the treatments would work, their own fears of getting better (i.e., being "locked into the idea that they are sick"), and fears of losing their service-connection. Another important finding was that the majority of PCTs offered Veterans preparatory groups (e.g., psychoeducation, coping skills) prior to beginning PE or CPT, reflecting a perception that Veterans must be "ready" to engage in these treatments. In doing so, the typical length of time Veterans spend receiving care within PCTs varies widely but trends significantly upward beyond the 12 session guideline for EBPs; one director reported having a "very linear 32-52 week program," while others described a situation where Veterans diagnosed with PTSD remained within the PCT "for life," without clear guidelines on how to discharge or refer them. It seems that the current state of affairs regarding Posttraumatic Stress Disorder is that things are somewhat in flux; the prevailing wisdom has shifted from a chronic condition requiring long courses of treatment to a condition that may be alleviated with brief treatments.

\section{Guiding Conception Summary}

The psychological literature points to the benefits of trauma-focused, exposure-based treatments for Veterans suffering from PTSD. However, there is also data suggesting that some Veterans, especially older Veterans (e.g., Vietnam-era), may view their illness as chronic and may not be amenable to engaging in these treatments. In addition, there are emerging findings that novel treatments involving writing (i.e., Written Exposure Therapy) may be effective in reducing PTSD symptoms with the added benefit of greater tolerability. Finally, there is data indicating that in the real-world, in order to provide patient-centered care, Veterans are often "prepped" for evidence-based treatments such as Prolonged Exposure and Cognitive Processing Therapy, although there is controversy in the literature as to whether that is necessary. To provide my clients Alex, Bruno, and Charles with the most effective and patient-centered course of therapy possible, the guiding conception of their treatment involved a stepped-care model for treating PTSD, where they were initially offered Written Exposure Therapy and subsequently offered the option to "step up" to Prolonged Exposure. All Veterans attended one initial assessment session prior to engaging in treatment and one treatment planning session between steps one and two of the treatment. From a public health perspective, the optimal outcome 
would be Veterans achieving PTSD symptom remission after Step 1 and not engaging in Step 2.

\section{A. ${ }^{1}$ ALEX'S ASSESSMENT: PRESENTING PROBLEMS, GOALS, STRENGTHS, AND HISTORY}

\section{Presenting Problems}

Alex presented for treatment to "get my wife off my back!" He reported that they had been having marital conflict over the past four years upon his return home from Iraq. Alex's wife drove him to the clinic for the initial assessment session and all subsequent appointments because he has avoided driving since experiencing the IED blast. They agreed this has been particularly problematic due to Alex being limited in terms of employment opportunities based on an inability to drive to work. She requested to be present for part of the initial assessment to offer her perspective on Alex's difficulties and their effect on the marriage.

Alex's wife stated that Alex has been "twitchy" and "aloof" ever since he returned home, which has created distance between them. In addition, she said that "he doesn't want to do anything anymore," and described him as "a shell of himself" in comparison to the man he was prior to his tour in Iraq; she said his unemployment has been "financially stressful at times" for their family. Alex talked about "feeling terrified about everything," especially loud noises, which cause him to "jump out of my skin.” His wife has learned not to approach him from behind because one time she tapped him on the shoulder and he "almost knocked her head off" in an attempt to protect himself. Alex also spoke of having concentration issues "whenever I try to focus," where memories of the IED blast would "come into my brain out of nowhere," and he would then "sit around blaming myself for a while," causing him to feel depressed. He noticed that he was more likely to "get pissed off" when he was having pain in his left knee, which was injured in the IED blast; although he had surgery to repair the knee, he still reported experiencing significant pain.

\section{Assessment and Diagnosis}

All three clients-Alex, Bruno, and Charles-were administered the same standardized assessment measures. This is illustrated below by the procedures in Alex's assessment.

\section{Clinically Assessing Symptoms}

During the initial assessment session, Alex was administered a structured interview to assess PTSD symptoms. To aid in this process, the Clinician-Administered PTSD Scale for DSM-5 past-month version (CAPS-5; Weathers, Blake, Schnurr, Kaloupek, Marx, \& Keane, 2013) was employed. Considered the "gold standard" in PTSD assessment, the CAPS-5 is a 30item structured interview used to diagnose PTSD and to assess PTSD symptom severity over the past month. The CAPS- 5 assesses the 20 core symptoms of PTSD as defined by the DSM-5 and

1

The next nine sections are numbered 4A-6A, 4B-6B, and 4C-6C, respectively, to indicate their parallel to sections 4-6 of a typical pragmatic case study (Fishman, 2013)—specifically: 4) Assessment of the Client's Problems, Goals, Strengths, and History; 5) Formulation and Treatment Plan; and 6) Course of Therapy. Chapters 4A-6A describe Alex's therapy; Chapters 4B-6B, Bruno's therapy; and Chapters 4C-6C, Charles' therapy. 
allows the interviewer to rate along five-point ordinal scales the severity of each symptom (a combination of frequency and intensity), the impact of symptoms on the client's social and occupational functioning, the overall severity of the symptom complex, and the global validity of ratings obtained. The CAPS-5 yields both dichotomous (i.e., present or absent) and continuous (i.e., severity) scores for each symptom and for the disorder as a whole. During Alex's assessment, the CAPS-5 was used to make a PTSD diagnosis but total scores were not tabulated due to the PCL-5 being selected as the outcome measure for PTSD symptoms as well as there being a lack of available psychometric data on reliability and validity since the CAPS was recently revised to reflect DSM-5 criteria.

In addition, during the initial assessment session, three standardized, self-report measures were administered. The first two - the PTSD Checklist for DSM-5 (PCL-5; see below) and the Beck Depression Inventory-Second Version (BDI-II; see below)—were also subsequently filled out prior to each session. These functioned as the treatment's outcome measures. The initial scores on each of the measures are presented in Tables 1 and 2. Results of Alex's outcome measures were discussed throughout the course of therapy and helped guide treatment. The three measures are described below.

The PTSD Checklist for DSM-5 (PCL-5; Weathers, Litz, Keane, Palmieri, Marx, \& Schnurr, 2013). This measure was administered to assess Alex's PTSD symptoms. The PCL-5 is comprised of 20 items (scored from 0 to 4 points each) with a score range of 0 to 80 , where higher scores reflect increasing PTSD symptom severity. These authors note that due to DSM-5 changes in PTSD symptom criteria, the PCL-5 scores are incompatible with PCL for DSM-IV scores; as such, they proposed using a cut-off score of 38 to interpret the presence of PTSD until further psychometric data was collected. ${ }^{2}$ Alex's PCL-5 score was a 60 at the start of treatment, indicating he was experiencing substantial PTSD symptoms. Fluctuations in his PCL-5 scores can be seen in Table 1.

The Beck Depression Inventory_-Second Version (BDI-II; (Beck, Steer, \& Brown, 1996). This measure was administered to assess Alex's depressive symptoms. The BDI-II is comprised of 21 items (scored from 0 to 3 points each) and higher scores reflect increasing depressive symptom severity. (Beck, Steer, \& Brown, 1996). Scores range from 0-63, where 13 is indicative of minimal depression; 14-19 suggests mild depression; 20-28 implies moderate depression; and 29-63 reflects severe depression (Beck et al., 1996). Alex's BDI-II score was an 18 during the initial assessment, indicating that he was experiencing mild symptoms of depression. Based on this, he was assessed for the presence of depressive disorders and bipolar and related disorders; when he did not meet criteria for any of these disorders, his depressive symptoms were conceptualized as secondary to his PTSD symptoms (i.e. it was hypothesized that by alleviating PTSD symptoms the depression would remit on its own). Fluctuations in his BDI-II scores can be seen in Table 2.

\section{The Life Events Checklist for DSM-5 (LEC-5; Weathers, Blake, Schnurr, Kaloupek,}

${ }^{2}$ Editor's note: As pointed out by Sloan and Marx’s commentary (2017, this issue), since Austern's case study was completed, further research by Wortmann et al. (2016) indicates that the cut-off score should be further adjusted down to 33. 
Marx, \& Keane, 2013). This measure is a self-report screening measure for potentially traumaticevents over someone's lifetime; it was developed for use in conjunction with the CAPS to help determine the index trauma and facilitate assessment of Criterion A stressors. Alex initially identified several stressful events (e.g. his younger brother passing away due to Sudden Infant Death Syndrome when Alex was four years old, being the victim of armed robbery as a teenager) but he ultimately selected the IED blast as the index trauma based on the fact that "it messed me up the most." Alex reported that he was driving a Humvee during a convoy mission near Tikrit when there was an IED blast that resulted in physical injury to him and killed several of his close friends. This event was consistent with DSM-5 Criterion A stressor requirements. For the purposes of the clinical interview, he was assessed for symptoms of PTSD in relation to this event.

Alex reported being "somewhat troubled" by having intrusive memories of the IED blast "a few times a week," often after he experienced knee pain but occasionally un-cued; this met criteria for one past month intrusion symptom of moderate severity (i.e., coded as 2 on a 0-4 scale) and thus met Criterion B. He also reported avoiding reminders of the trauma (i.e., not driving since the IED blast) since it occurred, which met criteria for one past month avoidance symptom of extreme severity (i.e., coded as 4) and thus met Criterion C. In addition, he reported thinking that "the world is completely dangerous" after the IED blast occurred and has consistently blamed himself for driving into the blast; this met criteria for two past month markedly elevated negative alterations in cognitions and mood symptoms (i.e., coded as 3 ) and thus met Criterion D. He also reported having frequent concentration issues and "jumpiness" at loud noises/being surprised by people (i.e., exaggerated startle response) since the IED blast occurred, which met criteria for two past month markedly elevated alterations in arousal and reactivity (i.e., coded as 3) and thus met Criterion E. Alex's symptoms have persisted for more than one month (i.e., Criterion F), have caused him significant social and occupational impairment (i.e., Criterion G), and were not due to medication/substances (i.e., Criterion H). He thus met full criteria for Posttraumatic Stress Disorder (changes in his diagnoses can be seen in Table 4).

\section{Relevant History}

Alex was born and raised in a working-class suburb of a large Northeastern city, by his biological mother and father, as the eldest of two boys. When he was four, his younger brother passed away from Sudden Infant Death Syndrome. Although he reported having a "good, loving environment” at home, and reported feeling particularly close to his mother, he acknowledged that she was "pretty overprotective." Alex stated that his mother was "very opposed" to him joining the Army because he was "a straight A student," but the family could not afford to pay for college and when he didn’t earn any scholarships he decided that "I didn’t want to end up with piles of student loan debt.”

He enlisted upon graduating from high school in June of 2006 and was trained through the $58^{\text {th }}$ Transportation Battalion, stationed at Fort Leonard Wood in Missouri. He married his high school sweetheart in July of 2008, shortly before he was deployed to Iraq that fall. Alex’s Military Occupational Specialty (MOS) was 88M-Motor Transport Operator, and he was responsible for driving a Humvee on convoy missions. He described his time in Iraq as 
"mostly uneventful...just lots of moving equipment around," until he experienced the IED blast, which was part of a large-scale insurgent-coordinated attack in August 2010.

Because Alex's tour was scheduled to end in September, he was flown back to the United States and had surgery on his knee at Walter Reed National Military Medical Center, at which time he received an honorable discharge for medical reasons; he retired from the Army at the rank of Sergeant (E-5). After Alex recovered from the injury, he and his wife moved back to the town where they grew up and he began taking online business courses at The University of Phoenix due to not wanting to drive to class at the local community college. He earned a Bachelor of Science with a concentration in Finance and had been doing online stock trading from his home over the past several years. Alex has also earned money playing online poker, which took up a considerable amount of his time. Although these two endeavors became increasingly profitable, his wife was concerned that he didn’t have "a real career" and was "becoming a hermit" due to the long hours he spent in his office on the computer. Additionally, she was "nagging the hell out of me" about having children, which Alex stated he was "nowhere near ready for."

\section{Goals and Strengths}

After Alex received diagnostic feedback that he had PTSD, he expressed the wish to "get better for my wife." As this was Alex’s first experience with individual therapy, he was unsure how to articulate specific treatment goals. He did say that he "hoped to get over this and get on with my life," although he appeared to be ambivalent about getting behind the wheel of a car again. In spite of that, Alex presented with notable strengths. He was very bright, with an entrepreneurial sense. In addition, he seemed to be invested in repairing his marriage and thus working on reducing his PTSD symptoms.

\section{A. ALEX'S CASE FORMULATION AND TREATMENT PLAN}

\section{Formulation}

When Alex experienced the IED blast, he subsequently developed a fear network in memory, which is a structure containing information about stimuli, responses, and meanings associated with the event. Through classical conditioning, the traumatic event (i.e., the IED blast), an unconditioned stimulus, became associated with conditioned stimuli (e.g., loud noises, driving), which began eliciting conditioned fear responses (e.g., increased heart rate, sweating). Whenever Alex was reminded of the IED blast via external or internal reminders, he had experienced physiological symptoms (i.e., fight or flight) designed to elicit escape and avoidance behavior, which he had consistently performed. Thus, the fear network functions like a computer program for escaping danger.

However, Alex's fear network became pathological upon his return to the United States because its associations among stimuli no longer represented the world accurately (i.e., his new environment was no longer dangerous), although he continued to avoid. In doing so, Alex had unknowingly developed and maintained PTSD because avoidance had prevented him from engaging in corrective emotional learning. Alex likely developed negative beliefs about himself 
and the world (e.g., "I am to blame for the event," "The world is dangerous," and "I am incompetent”). By avoiding situations that could disconfirm these beliefs (e.g., driving), Alex has continued to suffer from PTSD. Furthermore, by avoiding pleasurable activities and isolating from most people since he returned from Iraq, Alex has lost contact with positive reinforcement opportunities and thus has likely developed depressive symptoms. These symptoms are also maintained through avoidance as well as through Alex's negative beliefs about himself, which trigger feelings of guilt.

\section{Treatment Plan and List of Treatment Goals}

Goal 1: Provide a rationale for treatment, establish rapport, and create a safe/validating therapeutic environment

Because Written Exposure Therapy is designed with little therapist-client contact in mind, it was especially important to build rapport during the initial assessment session. As this was Alex's first therapy session ever and he was reportedly seeking treatment for his wife's benefit, I wanted to create a safe space where he felt comfortable enough to discuss his trauma and associated symptoms. I also wanted to provide him with information regarding the empirical support for both Written Exposure Therapy and Prolonged Exposure, as well as discuss the similarities and differences between the treatments and explain the rationale for engaging in Stepped Care for PTSD.

Goal 2: To decrease Alex's PTSD symptoms to a PCL-5 score below the suggested cutoff for $\underline{\operatorname{PTSD}(<33)}$

Written Exposure Therapy is hypothesized to work by blocking avoidance of the traumatic memory through repeated written exposures to it, which facilitates emotional processing and habituation of conditioned negative emotional responses, thus reducing PTSD symptom intensity. Alex's initial PCL-5 score of 60 would need to drop at least 27 points for him to no longer meet criteria for PTSD based on a suggested cutoff score of 33. If Alex's PTSD symptoms do not improve after he completes WET, he will be given the option of stepping up to Prolonged Exposure, which is hypothesized to reduce PTSD symptoms through imaginal and in vivo exposures.

Goal 3: To increase Alex's mastery over confronting the trauma memory and feared situations by reducing avoidance.

If Alex chooses to engage in Prolonged Exposure therapy, he will learn about subjective units of distress ratings in order to generate an in vivo exposure hierarchy, featuring increasingly challenging situations that remind him of the IED blast as well as behavioral activation-based situations he may also be avoiding (e.g., physical intimacy with wife). He will also engage in imaginal exposures to the memory of the IED blast and process the exposure experience with nondirective statements (e.g., education about trauma reactions, paraphrasing, reiterating the treatment rationale, and normalizing reactions). To help accomplish this goal, Alex will complete daily homework of listening to a recording of his imaginal exposure as well as completing in vivo exposures each day. 


\section{A. ALEX'S COURSE OF TREATMENT}

\section{Session 1: Assessment, Treatment Planning, Establishing Rapport (3 hours)}

Several weeks prior to the initial assessment session, Alex's wife called our program and attempted to schedule a preliminary appointment for him without his knowledge. She was informed that Alex himself would need to make contact by going through the state's Vet 2 Vet helpline, who would facilitate the referral to our program. At that time she stated "I'm really worried about him... and I don't think he's going to help himself.” However, Alex did in fact ultimately contact Vet 2 Vet and was authorized for free treatment through our program.

At the beginning of the session I explained confidentiality and its limits and obtained Alex's informed consent for me to audio-record the assessment for supervision purposes, clarifying my role as a psychology trainee. "Oh great, so he has no idea what he's doing!" he joked. Alex's wife left the session after approximately ten minutes, at which point he began fidgeting and nervously tapping his foot. I created an agenda for the session by explaining the different assessment tasks it would be helpful for him to complete, and set aside time for treatment planning informed by the assessment results; Alex declined an opportunity to add items to the agenda.

I began the assessment by having Alex fill out self-report measures (i.e., PCL-5, BDI-II), which I followed up with an unstructured interview to ask additional diagnostic questions and obtain relevant information across life domains. Although Alex was cooperative throughout the interview, he appeared to be growing impatient with the process, as he often glanced at his watch and pulled out his cell phone; based on this, I offered him a short break and he spent five minutes in the waiting room with his wife. I heard him yell "I'm not going back in there!" and she pleaded with him "Please baby...you can do this!” When Alex returned to the therapy room, I explained that I had overheard his comments and expressed interest in his concerns. He said, "I just want to get out of here...this is taking forever, let's finish this shit.” I concluded the assessment part of the session by administering the LEC-5 and CAPS-5, after which I gave him another brief break so I could score the assessment measures.

Alex wanted his wife to be present for the feedback part of the session so they returned together from his break. I explained that he met criteria for Posttraumatic Stress Disorder and that his depressive symptoms appeared to be secondary to PTSD. "So now what...am I completely screwed?” he asked. "Alex, you're definitely not screwed, we're going to fix this," his wife replied, attempting to reassure him. I provided him with psychoeducation about PTSD etiology and prognosis, the evidence base regarding PTSD treatments, and his treatment options. "I don’t want to take medication,” he said. “A buddy of mine went on an anti-depressant and gained a bunch of weight and couldn't get it up anymore." He sighed deeply and looked as if he were about to cry.

I assured him that there were effective behavioral treatments for PTSD and briefly described Prolonged Exposure and Cognitive Processing Therapy, as well as novel treatments such as Written Exposure Therapy and Virtual Reality Exposure Therapy. He put his head in his 
hands and appeared to be overwhelmed. "Maybe if you did that Prolonged one you'd be able to drive again?” his wife suggested. Alex balked, “I don't know if I'm ready for that...I'll try the writing and then depending on how that goes we'll see..." Given that he had no concrete treatment goals of his own, we collaborated on the goals of working together to reduce his PTSD symptoms as well as "increasing my confidence" in approaching feared situations. To accomplish these goals, Alex agreed to engage in a stepped-care treatment where the initial step was Written Exposure Therapy with the option of "stepping-up” to Prolonged Exposure. We had some challenges scheduling his next session due to his wife needing to drive him to the clinic and her work schedule did not leave much availability, but we ultimately found a time to meet. Session 2: Written Exposure Therapy Session 1 (60 minutes)

Alex arrived 15 minutes late to the clinic because "my goddamn wife wasn't home from work in time to get me here!” I suggested that he call me in the future if he were running late and reminded him of my contact information at the clinic. Because he was late to arrive, I had him fill out self-report measures (i.e., PCL-5, BDI-II) in the therapy room instead of the waiting room. “These again?” he grumbled. I explained how these inventories could function as outcome measures and indicate whether the therapy was helping him; he appeared to understand this rationale. After quickly checking his response to item 9 on the BDI-II to ensure he was not endorsing any suicidal ideation, I informed him that we would begin Written Exposure Therapy today. "Super,” Alex mumbled sarcastically.

The first twenty-five minutes of the session involved me re-educating him about the symptoms of PTSD and reminding him of the rationale for written exposure. We discussed how he experienced changes in his physical reactions, emotions, thoughts, and behaviors in response to the IED blast. "Yeah, it messed me up...I've avoided everything-people, driving," he said. As per the treatment manual, we explored the consequences of Alex's avoidance, which he acknowledged "wasn't such a problem at first but now it's affecting my marriage.” Furthermore, he questioned whether he was becoming a "workaholic," given the amount of time he was spending trading stocks and playing poker online. I provided him with psychoeducation regarding how to measure his anxiety level using subjective units of distress (SUDS), which is a 0 -100 scale where $0=$ no anxiety and $100=$ the most anxiety he has ever felt. I normalized that he may experience his highest SUDS level during the initial writing session but his anxiety would likely decrease by the final writing session.

At that point, I gave Alex the writing instructions, which included general directions for all of the writing sessions as well as specific instructions for the first session. I informed him that I would like him to write about the IED blast without worrying about spelling or grammar, in as much detail as possible, for 30 minutes without stopping. He was instructed to include details on how the IED blast happened, the involvement of other people involved, what he was feeling and thinking as the trauma was happening, and his very deepest emotions and thoughts about it now. For the first writing session, Alex was instructed to start at the beginning of the memory and was encouraged to include sensory details, and also to include the thoughts and feelings he experienced during and immediately after the trauma. He was also reminded that the trauma was not actually happening again, but he was simply recounting it. Finally, he was instructed to provide SUDS ratings before he started writing and after he had finished. 
I let Alex know that I would be leaving the therapy room to give him privacy while he wrote and that I would return in 30 minutes; if, in the meantime, he had any difficulties he could find me in the adjacent room. I also let him know that I would be briefly checking his writing to confirm that he had written about the IED blast, but it would be up to him whether he wanted me to read the entire essay in detail.

When Alex didn't have any questions, I left the room and set a 30 minute alarm to keep track of the time. At that point, I returned to the room and found Alex playing a video game on his cell phone. However, he claimed he had written for 25 of the 30 minutes. I requested permission to read his writing, which he agreed to. He had completed the writing assignment and it did appear that he had written about the IED blast, per instructions. His pre-SUDS rating was 90 and his post-SUDS rating was 75. “Can I leave now?” he asked. I inquired whether he experienced any difficulties during the writing session and he said "Yeah, that completely sucked," although he would not elaborate. I normalized his feelings, as well as the likelihood that he would experience thoughts and feelings related to the trauma during his week; he was instructed not to avoid these thoughts and feelings when they arose, but rather to allow them to be present.

\section{Session 3: Written Exposure Therapy Session 2 (45 minutes)}

After the initial session of Written Exposure Therapy, Alex left me a somewhat cryptic voicemail that said "I’ve been thinking about my treatment...give me a call back.” Upon reaching him, he stated, "I don't see the point of coming in anymore. I mean, I can just write on my own at home and then email it to you. That way, I don't have to deal with getting my wife to drive me." I validated his frustration and asked if he would be willing to attend the next session to discuss this in person, which he reluctantly agreed to. That week he arrived to session several minutes early due to his wife getting off work early, and he filled out the PCL-5 and BDI-II in the waiting room. Again, I checked his response to item 9 on the BDI-II to ensure he was not endorsing any suicidal ideation.

We discussed the phone conversation we had several days earlier and I explained to Alex that research has shown that people do better when they visit the clinic in person to complete their writing, as opposed to writing at home (Sloan, personal communication). I also reminded him that we don't want to reinforce avoidance and speculated whether his desire to write from home primarily functioned as a way to avoid driving to the clinic. Although Alex did not have an answer to that question, he agreed to continue coming to the clinic for therapy.

Given his behavior last week, I asked him if he would be willing to have me hold onto his cell phone while he completed the writing today. "Fine, fine... whatever," he said. He was instructed to write about the IED blast again in as much detail as possible for 30 minutes and to rate his SUDS beforehand and afterward. I left the room and returned 30 minutes later, requested permission to check his writing and confirmed it was about the IED blast, and recorded his SUDS ratings of 80 (pre) and 60 (post). As he did not report any difficulties or concerns, I reminded him that he would likely experience thoughts and feelings related to the trauma during his week; he was again instructed not to avoid these thoughts and feelings when they arose, but 
rather to allow them to be present.

\section{Sessions 4-6: Written Exposure Therapy Sessions 3-5 (45 minutes each)}

These sessions were structurally identical to sessions 1 and 2 of Written Exposure Therapy, with the distinction that the writing instructions had some modifications. In session 3 of WET, Alex was invited to focus on the most distressing part of the memory as opposed to writing about the entire memory. In addition, he was encouraged to write about how the IED blast had changed the way he viewed his life, the meaning of life, and how he related to other people. During session 3 of WET, Alex's pre-SUDS were a 75 and his post-SUDS were a 50; he completed the writing assignment as instructed, focusing on the moment when he realized that his passenger in the Humvee had been killed in the blast. Again, he was instructed not to avoid thoughts and feelings between sessions.

In session 4, with the exact same writing assignment, his pre-SUDS were a 65 and his post-SUDS were a 45 .

Finally, in session 5, the assignment included the instruction for Alex to write about how the IED blast related to his current life and to his future; his pre-SUDS were a 50 and his postSUDS were a 25.

Prior to each of these three sessions, he filled out the PCL-5 and BDI-II in the waiting room. He did not endorse suicidal ideation at any point during the treatment. During these sessions, Alex appeared more cooperative than he was at the beginning of treatment. When asked about that, he said “I don't know, man. I guess I'm so close to being done.”

\section{Session 7: Treatment Planning and Termination (90 minutes)}

Alex initially "no showed" for this session. When I called him, he said he had "gotten busy that day playing poker" and refused to leave in the middle of a tournament to attend therapy. He agreed to reschedule the session and sounded relieved that he was not in trouble.

As usual, his wife drove him to the clinic and she also attended this session, per his request. After he filled out self-report measures, I provided Alex with his PCL-5 and BDI-II scores over the course of WET; his PCL-5 dropped from a 60 to a 40 and his BDI-II dropped from an 18 to a 12. "Wow, I'm glad I stuck it out," he said. Although he exhibited reductions in both PTSD and depressive symptoms, he was slightly above the suggested cutoff score of 33 for probable PTSD. However, he was experiencing fewer intrusions, improved concentration, and a shift in his thinking away from blaming himself for the IED blast.

Alex and I discussed whether it made sense for him to begin Prolonged Exposure at that time given the fact he still met criteria for PTSD based on his PCL-5 score. Ultimately, he decided that he wanted to take a treatment break so he could "focus on work" and "get back to my marriage," which he reported had improved slightly. His wife agreed, "He's doing a lot better, even if he doesn't see it all the time.” Although I praised the substantial progress he made, I raised some concerns that he was still avoiding driving and reminded him that Prolonged 
Exposure would explicitly target that symptom through in vivo exposures. Alex verbalized understanding of this but said that he did not want to invest the time into doing PE when many of his PTSD symptoms had improved. His wife had an alternative viewpoint: "I think he likes having me as his chauffeur," she said, laughing.

Although Written Exposure Treatment was designed to have little therapist and client interaction, I nonetheless attempted to process our termination with Alex. He had difficulty expressing thoughts about our work ending, what it was like to share his trauma with me, and whether he had any concerns about maintaining his gains. As I started to remind him to continue allowing thoughts and feelings about the trauma to be present, he interrupted me by saying, "I know, I know... avoidance is the enemy.” We both laughed.

Before we said goodbye, I had Alex fill out an additional self-report inventory assessing his satisfaction with the treatment. The Client Satisfaction Questionnaire-8 (CSQ 8; Larsen, Attkisson, Hargreaves, \& Nguyen, 1979) is a self-report measure containing eight items that are rated on a 4-point Likert-type scale, with higher scores indicating greater treatment satisfaction. The CSQ-8 has good test-retest reliability, internal consistency, and sensitivity to treatment (Nguyen, Attkison, \& Stegner, 1983). He reported being mostly satisfied with Written Exposure Therapy, as evidenced by his high CSQ-8 score, but said that "I still think I could have done this on the computer!" He also mentioned that it was helpful when I requested permission to read his writing, which made him feel like he "had some control over the whole thing." I wished him well and reminded him that he was welcome to return to our program should he change his mind about receiving additional treatment.

\section{B. BRUNO'S ASSESSMENT: PRESENTING PROBLEMS, GOALS, STRENGTHS, AND HISTORY}

\section{Presenting Problems}

Bruno presented for treatment to "finally deal with my PTSD.” He reported that he had avoided psychotherapy for more than two decades and had attempted to manage his symptoms with alcohol. After spending the past 8 months at a community halfway house focused on longterm residential substance use recovery, Bruno hoped to complete PTSD treatment during his final 4 months at the facility before attempting to live independently.

He spoke of "having freak outs" whenever he would be reminded of the trauma, which had occurred during basic training thirty years ago when he was raped by another Naval recruit in the showers. According to Bruno, these "freak outs" typically happened when he encountered men who reminded him of the perpetrator, as well as when he encountered locations that reminded him of the rape (e.g., stall showers, claustrophobic spaces). In those moments he experienced extreme panic symptoms and frequently fled the situation, needing to "get the hell out of there!”

Bruno also endorsed engaging in frequent "scanning and checking," where he would ensure that nobody could position themselves behind him. If possible, he preferred to avoid those situations entirely, partly out of fear that he would be harmed and partly out of fear that he would 
experience such intense anger that he "might explode." He stated that "there's been a volcano inside me" since the rape, and he occasionally "breaks things" in anger. Bruno discussed how the "unpleasant thoughts" about the rape made him feel "so ashamed of myself" and he tried to push them out of his mind by distracting himself and "numbing the pain" with alcohol.

According to Bruno, it was “my fault I didn’t fight him off” and he blamed himself for never reporting it; he said that he has only disclosed it to civilian healthcare providers since leaving the Navy, as "I didn't want to find out what would have happened if I told anyone." Bruno stated that the more shameful he felt, the more he isolated at home and drank, which "ultimately ruined my marriage" and "made me a lousy father." Although his children were supportive of his recent sobriety, he nonetheless expressed difficulties connecting with them; "it’s a work in progress," he declared.

\section{Assessment and Diagnosis}

During the initial assessment session, I conducted an unstructured clinical interview with Bruno and also administered the same measures that Alex received during his initial assessment session. These included the CAPS-5, PCL-5, BDI-II, and LEC-5. The PCL-5 and BDI-II functioned as the treatment's outcome measures, so he filled them out at the beginning of each subsequent session. The initial scores on each of the measures are presented in Tables 1 and 2. Results of his outcome measures were discussed throughout the course of therapy and helped guide treatment.

When filling out the LEC-5, Bruno identified two stressful events that "still haunt me to this day." In addition to the rape, he reported watching a man drown when he was stationed overseas, which he claimed was still "quite distressing” to him; both of these events were consistent with DSM-5 Criterion A stressor requirements. Because Bruno was waffling over which event distressed him more currently, I asked him which one he wanted to talk about least with me, to which he answered "I guess....the rape.” For the purposes of the clinical interview, he was assessed for symptoms of PTSD in relation to this event.

Bruno reported being "very distressed" when he experienced reminders of the rape "a few times a week." This met criteria for one past month intrusion symptom of moderate severity (i.e., coded as 2 on a $0-4$ scale) and thus met Criterion B. He also reported avoiding thoughts of the trauma (i.e., pushing thoughts out of his mind) "whenever I can,” which met criteria for one past month markedly elevated avoidance symptom (i.e., coded as 3) and thus met Criterion C. In addition, he reported thinking that "I am completely to blame" after the rape occurred and has felt ashamed consistently since then; this met criteria for two past month negative alterations in cognitions and mood symptoms of extreme severity (i.e., coded as 4) and thus met Criterion D. He also reported having occasional "anger outbursts" (e.g., punching holes in walls) as well as frequent "scanning and checking," which met criteria for two past month markedly elevated alterations in arousal and reactivity (i.e., coded as 3) and thus met Criterion E. Bruno's symptoms have persisted for more than one month (i.e., Criterion F), have caused him significant social and occupational impairment (i.e., Criterion G), and were not due to medication/substances (i.e., Criterion H). He thus met full criteria for Posttraumatic Stress 
Disorder (changes in his diagnoses can be seen in Table 3).

The PCL-5 was administered to assess Bruno’s PTSD symptoms and his PCL-5 score was a 72 at the start of treatment, indicating he was experiencing severe PTSD symptoms. Fluctuations in his PCL-5 scores can be seen in Table 1.

The BDI-II was administered to assess his depressive symptoms and Bruno’s BDI-II score was a 21 during the initial assessment, indicating that he was experiencing moderate symptoms of depression. Based on this, he was assessed for the presence of depressive disorders and bipolar and related disorders; when he did not meet criteria for any of these disorders, his depressive symptoms were conceptualized as secondary to his PTSD symptoms (i.e., it was hypothesized that by alleviating PTSD symptoms the depression would remit on its own). Fluctuations in his BDI-II scores can be seen in Table 2. Bruno was also assessed for the presence of substance use disorders and he met criteria for Alcohol Use Disorder, in early remission, in a controlled environment.

\section{Relevant History}

Bruno was born and raised in a rural Guatemalan village, as one of eight children to his biological parents. He stated that he grew up in "a tiny house," which he shared with a large extended family network including cousins, aunts and uncles, and grandparents. "We were poor but happy," he mused. However, his father decided that their family should flee the country for the United States due to safety concerns and unemployment during the Guatemalan Civil War in the early 1980s. Bruno said he experienced "a huge culture shock” after the family illegally immigrated to Texas; “it was very stressful...most of us couldn't speak English, and my father was caught up in a huge legal battle after Reagan initially denied our asylum petition.” Bruno rationalized that "I probably tried to Americanize myself too much," noting that he "tried as hard as possible to fit in," which resulted in him getting recruited by the Junior Reserve Officers' Training Corps (JROTC) when he was 17 years old. Unfortunately, this caused significant conflict based on Bruno's family's ambivalence toward the U.S. government, which visibly contrasted with his own jingoism.

After his family was ultimately naturalized and became American citizens, Bruno enlisted upon graduating from high school in June of 1985 and went to The Great Lakes Naval Training Center for boot camp. Several weeks into basic training, he reported that he was physically attacked and raped by the Recruit Chief Petty Officer while he was taking a shower. He stated that he did not report the incident "out of fear," given that the RCPO said "he would murder me and my family if I squealed."

Bruno completed boot camp by "pretending that it never happened” and subsequently went to submarine school in Groton, CT to become a mess management specialist (Navy Enlisted Classification = MS-0000) on submarines, with the goal of someday running the White House Mess for the President of the United States. After completing "A" school (i.e., technical training) and then Navy Basic Enlisted Submarine School (BESS), he was assigned to the submarine USS Pittsburgh; his first sea tour involved deployments to the Mediterranean Sea, the Persian Gulf, and the North Atlantic Ocean. Although Bruno ambitioned to be a Navy careerist, 
he "couldn't handle the claustrophobia" of the submarine and began drinking during port calls and upkeep maintenance periods "to cope.” Meanwhile, he had begun "acting strangely” aboard the submarine and the Hospital Corpsman ultimately demanded he receive a psychological evaluation at Naval Health Clinic New England in Groton.

In October 1991, after the USS Pittsburgh returned from the North Atlantic, Bruno was evaluated by Navy psychologists and was diagnosed with Adjustment disorder with mixed disturbance of emotions and conduct (309.40) and Alcohol abuse (305.00), based on DSM-III-R criteria. "Because I didn't tell the doctors about the rape, they just thought I couldn't handle life on the sub," he said. He stated that the Navy deemed him unsuitable to continue serving aboard the submarine and offered him a "surface reassignment," which Bruno declined "out of anger." He reported feeling "extremely hurt" and said that "his pride was wounded," so he opted to retire instead, receiving an honorable discharge from the Navy for medical reasons, at the rank of Petty Officer Third Class (E-4).

Because Bruno had "basically cut off all ties” to his family in Texas by then, he decided to remain in Connecticut, where he was already renting a room in a boarding house near the Naval Health Clinic. He leveraged his Navy culinary training into a line cook job at a local restaurant, where he met his soon-to-be wife, who was working as a server at the restaurant.

They married in 1993 and had two daughters together in 1995 and 1997, respectively.

However, Bruno’s alcoholism became "more and more of a problem” until he was fired from the restaurant and his wife gave him an ultimatum: "get help or get out." He agreed to meet with a psychoanalyst in the community but discontinued treatment after several sessions when "it felt like she was blaming me and my family for everything... [like] my father's decision to leave Guatemala. She told me I had a 'cauldron of rage bubbling under the surface'...After a few times I'd had enough of that."

Bruno and his wife divorced in 2000 and his wife received full custody of their daughters due to Bruno's alcohol use and unemployment. He "bounced around a lot" after that, occasionally finding work at restaurants and "living in shelters sometimes." Although he reportedly dated women, he stated that these relationships were "nothing serious." Bruno said that he has had "more contact" with his daughters over the past several years, and they have encouraged him to "get some stability going in my life."

\section{Goals and Strengths}

After Bruno received diagnostic feedback that he had PTSD he began to cry. "This is all my fault," he said, sobbing. "I never told anyone what really happened to me so they just thought I was freaking out about the sub...I could've gotten help twenty years ago.” As this was Bruno's first experience with Cognitive Behavioral Therapy (CBT), I made sure to provide him with psychoeducation around some of the differences between CBT and psychoanalysis. He stated that his goals for treatment were to "finally address the elephant in the room" and engage in trauma-focused treatment for the Military Sexual Trauma (MST) he experienced. He stated 
that he would continue to work toward maintaining sobriety with the halfway house treatment team and thus did not want to make that a focus of our work together.

Bruno presented with notable strengths. He was very intelligent, as evidenced by him learning English quickly and receiving a high score on the Armed Services Vocational Aptitude Battery (ASVAB). In addition, he seemed to be invested in repairing his relationships with his daughters and working on reducing his PTSD symptoms.

\section{B. BRUNO'S CASE FORMULATION AND TREATMENT PLAN}

\section{Formulation}

When Bruno was physically attacked and raped, he subsequently developed a fear network in memory, which is a structure containing information about stimuli, responses, and meanings associated with the event. Through classical conditioning, the traumatic event (i.e. the rape), an unconditioned stimulus, became associated with conditioned stimuli (e.g. the shower, large men), which began eliciting conditioned fear responses (e.g. increased heart rate, sweating). Whenever Bruno was reminded of the rape via external or internal reminders, he had experienced physiological symptoms (i.e., fight or flight) designed to elicit escape and avoidance behavior, which he had consistently performed. Thus, as in the other cases, the fear network functioned like a computer program for escaping danger.

However, Bruno’s fear network became pathological during his service aboard the submarine because its associations among stimuli no longer represented the world accurately (i.e., not all showers were dangerous, not all men were dangerous), although he continued to avoid. In doing so, Bruno had unknowingly developed and maintained PTSD because avoidance had prevented him from engaging in corrective emotional learning. Bruno likely developed negative beliefs about himself and the world (e.g. "I am to blame for the event," "The world is dangerous," and "I am incompetent”). By avoiding situations that could disconfirm these beliefs (e.g. being around men in enclosed spaces), Bruno has continued to suffer from PTSD.

Furthermore, he began abusing alcohol in order to avoid thinking about the rape as well as to numb the intense negative emotions that he experienced; although this provided him temporary relief, it resulted in long-term negative consequences (e.g. marital discord, job loss).

Bruno’s depression likely developed and was subsequently maintained by a loss of positive reinforcement opportunities (stemming from isolation), alcohol abuse (physiological depressant), and maladaptive cognitions (e.g. "I am worthless”).

\section{Treatment Plan and List of Treatment Goals}

Goal 1: Provide rationale for treatment, establish rapport, and create a safe/validating therapeutic environment.

Because Written Exposure Therapy is designed with little therapist-client contact in mind, it was especially important to build rapport during the initial assessment session. As Bruno had reportedly had a negative therapy experience fifteen years earlier, I wanted to create a 
safe space where he felt comfortable enough to discuss his trauma and associated symptoms. I also wanted to provide him with information regarding the empirical support for both Written Exposure Therapy and Prolonged Exposure, as well as discuss the similarities and differences between the treatments and explain the rationale for engaging in Stepped Care for PTSD.

Goal 2: To decrease Bruno’s PTSD symptoms to a PCL-5 score below the suggested cutoff for PTSD $(<38)$.

Written Exposure Therapy is hypothesized to work by blocking avoidance of the traumatic memory through repeated written exposures to it, which facilitates emotional processing and habituation of conditioned negative emotional responses, thus reducing PTSD symptom intensity. Bruno's initial PCL-5 score of 72 would need to drop at least 34 points for him to no longer meet criteria for PTSD. If Bruno's PTSD symptoms do not improve after he completes WET, he will be given the option of stepping up to Prolonged Exposure, which is hypothesized to reduce PTSD symptoms through imaginal and in vivo exposures.

Goal 3: To increase Bruno’s mastery over confronting the trauma memory and feared situations by reducing avoidance.

If Bruno chooses to engage in Prolonged Exposure therapy, he will learn about subjective units of distress ratings in order to generate an in vivo exposure hierarchy, featuring increasingly challenging situations that remind him of the rape as well as behavioral activation-based situations he may also be avoiding (e.g. meeting new people, talking to his daughters). He will also engage in imaginal exposures to the memory of the rape and process the exposure experience with nondirective statements (e.g., education about trauma reactions, paraphrasing, reiterating the treatment rationale, and normalizing reactions). To help accomplish this goal, Bruno will complete daily homework of listening to a recording of his imaginal exposure as well as completing in vivo exposures each day.

\section{B. BRUNO'S COURSE OF TREATMENT}

\section{Session 1: Assessment, Treatment Planning, Establishing Rapport (3 hours)}

Approximately two months before meeting with Bruno for the first time, his case manager at the halfway house contacted me to inquire about the program at our clinic. She stated that she was working with a Veteran who was "distrustful of the military and the VA" and wanted to ensure that they "won't have to go to the large VA hospital” for treatment. She also wanted to know if the Veteran would be able to see a female therapist. I explained that the Veteran would not need to visit the state's VA hospital unless they were interested in receiving a compensation and pension exam through the Veterans Benefits Administration. I told her that some Veterans prefer receiving care through our program because our clinic "is very small and typically doesn't feel as overwhelming.”

However, I informed her that we could not guarantee the availability of a female clinician and instructed her that the Veteran would need to contact the Vet-to-Vet helpline in order to facilitate the referral to our program. One month later, Bruno was authorized for free treatment 
and I called him to schedule an initial assessment session; when he asked about the possibility of working with a female clinician, I let him know that there would be a significant wait, given our staffing load at that time. He opted to work with me instead of waiting because he hoped to complete treatment at our clinic in coordination with him moving out of the halfway house.

When I greeted Bruno in the waiting room, he appeared to be quite anxious based on his shaking legs, fast rate of speech, and difficulty making eye contact. However, once we approached the therapy room he started scanning the room and began pacing in circles near the door. "You want me to go in there with you?" he suddenly asked, sizing me up. I was puzzled by the question and caught off guard by his behavior, noticing that I was becoming anxious, too.

“That’s right. Are there any concerns you have?” I asked. “Listen doc,” he began. "I have a very hard time trusting other men, especially in tight quarters." I validated his concerns and explained that it would be helpful to meet in the therapy room to maintain his confidentiality. After he entered the room I suggested he sit near the door "to give him an easy exit” should he need it. I explained confidentiality and its limits and obtained Bruno's informed consent to me audio-recording the assessment for supervision purposes, clarifying my role as a psychology trainee. I created an agenda for the session by explaining the different assessment tasks it would be helpful for him to complete, and set aside time for treatment planning informed by the assessment results; Bruno declined an opportunity to add items to the agenda.

I began the assessment by having Bruno fill out self-report measures (i.e. PCL-5, BDI-II), which I followed up with an unstructured interview to ask additional diagnostic questions and obtain relevant information across life domains. Given his initial safety concerns, he was surprisingly cooperative throughout the interview. Nonetheless, I frequently checked in with him "to make sure you're doing okay" and offered him breaks "whenever you want.”

I concluded the assessment part of the session by administering the LEC-5 and CAPS-5, after which I gave him another brief break so I could score the assessment measures. I explained that he met criteria for Posttraumatic Stress Disorder, for Alcohol Use Disorder in early remission in a controlled environment, and that his depressive symptoms appeared to be secondary to PTSD and alcohol use. I provided him with psychoeducation about PTSD etiology and prognosis, the evidence base regarding PTSD treatments, and his treatment options, briefly describing Prolonged Exposure and Cognitive Processing Therapy, as well as novel treatments such as Written Exposure Therapy and Virtual Reality Exposure Therapy.

Bruno explained that he hoped to finish treatment in four months. "I'll be honest doc, I like the sound of the writing treatment because it's the quickest and it's the least amount of time.” We collaborated on the goals of working together to reduce his PTSD symptoms and he agreed to engage in a stepped-care treatment where the initial step was Written Exposure Therapy with the option of "stepping-up” to Prolonged Exposure. We scheduled the initial therapy session for the following week. 


\section{Session 2: Written Exposure Therapy Session 1 (60 minutes)}

Bruno arrived 30 minutes early for the session and the clinic receptionist later informed me that he had been pacing "non-stop" in the waiting room for several minutes before she was able to convince him to sit down so he could fill out self-report measures (i.e., PCL-5, BDI-II). After bringing him into the therapy room and quickly checking his response to item 9 on the BDI-II to ensure he was not endorsing any suicidal ideation, I informed him that we would begin Written Exposure Therapy today.

The first twenty-five minutes of the session involved me re-educating him about the symptoms of PTSD and reminding him of the rationale for written exposure. We discussed how he experienced changes in his physical reactions, emotions, thoughts, and behaviors in response to the rape. "It completely ruined my life," he said. "And then I made it worse by pretending it never happened.” As per the treatment manual, we explored the consequences of Bruno's avoidance, discussing how his alcohol use served an avoidance function for him. I provided him with psychoeducation regarding how to measure his anxiety level using subjective units of distress (SUDS), which is a 0-100 scale where $0=$ no anxiety and $100=$ the most anxiety he has ever felt. I normalized that he may experience his highest SUDS level during the initial writing session but his anxiety would likely decrease by the final writing session.

At that point, I gave Bruno the writing instructions, which included general directions for all of the writing sessions as well as specific instructions for the first session. I informed him that I would like him to write about the rape without worrying about spelling or grammar, in as much detail as possible, for 30 minutes without stopping. He was instructed to include details on how the rape happened, the involvement of other people, what he was feeling and thinking as the trauma was happening, and his very deepest emotions and thoughts about it now. For the first writing session, Bruno was instructed to start at the beginning of the memory and was encouraged to include sensory details, and include the thoughts and feelings he experienced during and immediately after the trauma. He was also reminded that the trauma was not actually happening again, but he was simply recounting it. Finally, he was instructed to provide SUDS ratings before he started writing and after he had finished.

I let Bruno know that I would be leaving the therapy room to give him privacy while he wrote and that I would return in 30 minutes; if, in the meantime, he had any difficulties he could find me in the adjacent room. I also let him know that I would like to briefly check his writing to confirm that he had written about the rape, but it would be up to him whether he wanted to me to read the entire essay in detail. Bruno didn't have any questions and so I left the room and set a 30 minute alarm to keep track of the time.

When I returned, I requested permission to read his writing, which he agreed to. He had completed the writing assignment and it did appear that he had written about the rape, per instructions. His pre-SUDS rating was 90 and his post-SUDS rating was 95. I inquired whether he experienced any difficulties during the writing session, and he said "That was awful, I'm never doing that again!” I normalized his feelings, as well as the likelihood that he would experience thoughts and feelings related to the trauma during his week; he was instructed not to 
avoid these thoughts and feelings when they arose, but rather to allow them to be present. "It doesn't matter because I'm not coming back," he threatened.

\section{Session 3: Written Exposure Therapy Session 2 (45 minutes)}

Because Bruno had signed a release of information form for me to communicate with his case manager, I called her prior to session 2 to inquire about his well-being and check in regarding his comments at the end of session 1 . She stated that she used motivational interviewing techniques when she met with him earlier in the week, and he was able to resolve some ambivalence about engaging in treatment; she assured me he would attend session. That week he arrived to session several minutes early and he filled out the PCL-5 and BDI-II in the waiting room without pacing. Again, I checked his response to item 9 on the BDI-II to ensure he was not endorsing any suicidal ideation.

I praised Bruno for attending session in spite of the distress he was experiencing. "Yeah, I guess I've been freaking out," he said. "All week I kept flashing back to what he did to me that day...I know I wasn't supposed to avoid the thoughts but I kept trying to distract myself.” He was instructed to write about the rape again in as much detail as possible for 30 minutes and to rate his SUDS beforehand and afterward.

I left the room and returned 30 minutes later; when I checked his writing to confirm it was about the rape, I noticed he had crumpled the paper into a ball. His SUDS ratings were 100 (pre) and 90 (post). When asked about any difficulties or concerns he may have had, he did not respond and just glared at me. I reminded him that he would likely experience thoughts and feelings related to the trauma during his week; he was again instructed not to avoid these thoughts and feelings when they arose, but rather to allow them to be present.

\section{Sessions 4-6: Written Exposure Therapy Sessions 3-5 (45 minutes each)}

These sessions were structurally identical to sessions 1 and 2 of Written Exposure Therapy, with the distinction that the writing instructions had some modifications. In session 3 of WET, Bruno was invited to focus on the most distressing part of the memory as opposed to writing about the entire memory. In addition, he was encouraged to write about how the rape had changed the way he viewed his life, the meaning of life, and how he related to other people.

During session 3 of WET, Bruno’s pre-SUDS were a 90 and his post-SUDS were an 85. However, he did not complete the writing assignment as instructed, because he did not zoom in any particular aspect of the memory. When I asked him about possible difficulties related to this, he jumped up and screamed "WHAT DID YOU WANT? PLAY BY PLAY OF THE BLOOD RUNNING DOWN MY LEG? THIS IS SICK!” I attempted to validate his concerns. Then I rereminded him of the rationale for focusing on the most distressing aspect of the memory and again he was instructed not to avoid thoughts and feelings between sessions.

In session 4, with the exact same writing assignment, his pre-SUDS were a 95 and his post-SUDS were a 90 . When I checked his writing, he did focus on a particularly distressing aspect of the memory, which was a vivid description of being left alone to cry in the shower 
afterward.

Finally, in session 5, the assignment included the instruction for Bruno to write about how the rape related to his current life and to his future; his pre-SUDS were an 80 and his postSUDS were a 75. Prior to these three sessions, he filled out the PCL-5 and BDI-II in the waiting room. He did not endorse suicidal ideation at any point during the treatment. During the final two sessions, Bruno appeared somewhat more cooperative than he was at the beginning of treatment; when asked about that, he stared at the ground and said "I just feel so ashamed."

\section{Session 7: Treatment Planning (90 minutes)}

Bruno's case manager contacted me prior to this session in order to coordinate his care and we discussed the possibility of Bruno continuing in therapy; she agreed to extend his stay at the halfway house until he was finished with Prolonged Exposure (should he choose to step up to step two) and until he had a solid aftercare plan in place. After he filled out self-report measures, I provided Bruno with his PCL-5 and BDI-II scores over the course of WET; his PCL-5 dropped from a 72 to a 54 and his BDI-II dropped from a 21 to an 18. "Then why don't I feel completely better?” he asked. We discussed how Bruno actually did notice several improvements in his functioning: he had a reduction in the frequency and intensity of the intrusions about the rape and he wasn't working as hard to avoid these intrusions when they occurred. Additionally, he was having fewer angry outbursts.

However, he was still experiencing some problematic symptoms, such as avoiding reminders and hypervigilance against possible threats. Although he exhibited reductions in both PTSD and depressive symptoms, he was still above the suggested cutoff for probable PTSD. Bruno and I discussed whether it made sense for him to begin Prolonged Exposure at that time. Because he was still avoiding situations that reminded him of the rape, I recommended Prolonged Exposure because it would explicitly target that symptom through in vivo exposures. “I don’t know, doc,” he said. “I’m afraid I won’t be able to handle it.” After I validated those fears, Bruno was able to access a source of motivation to do PE by thinking of what his daughters would want him to do. I had him fill out an additional self-report inventory assessing his satisfaction with the treatment (CSQ-8). He reported being very satisfied with Written Exposure Therapy, although he said "I wish it cured me."

\section{Session 8: Prolonged Exposure Session 1 (90 minutes)}

I called Bruno before our eighth session and first session of PE to remind him to bring an audio recording device so he could record the session. However, after he arrived and filled out self-report measures, he did not appear to have one with him and seemed somewhat ashamed about this, as he had poor eye contact with me. When I asked him about this, he said "Look, I went to Radio Shack to buy one and I couldn’t afford it, okay? It's embarrassing.” I empathized with him and praised him for trusting me enough to be honest about the situation; I also let him know that the DoD/VA created a smartphone app called "PE Coach" that features a recording device built in. Bruno shook his head sadly, “I don’t have a smartphone, doc.” Ultimately, I let Bruno borrow an extra audio recorder of mine for the remainder of his treatment and told him I would notify his case manager to ensure he returned it to me afterward. 
I provided Bruno with the treatment rationale and presented him with an overview of PE's structure. Instead of doing the complete trauma interview, which would have been redundant based on the assessment he already completed, I only asked questions which filled in any missing gaps and offered him the opportunity to share any additional details about the rape, which he declined. Afterward, we practiced breathing retraining for 15 minutes and he identified situations where he tends to hyperventilate and it would be beneficial to use relaxation skills.

When it was time to assign homework, Bruno looked at me strangely. "Homework?” he asked. "What am I back in school again?" I used math to illustrate the benefit of homework: "Well Bruno, you're here in session for 1 of 168 hours during your week. If you want to feel better, it’s going to take some practice.” By conceptualizing homework as “practice,” he was more amenable to engaging in the required assignments between sessions 1 and 2, which were to use deep breathing three times a day for 10 minutes each time, to listen to the recording of the session once, and to read the rationale for treatment in his workbook.

\section{Session 9: Prolonged Exposure Session 2 (90 minutes)}

After Bruno arrived and filled out self-report measures, I checked in with him about homework completion, which he said he did, and we set an agenda for the session. During the first part of the session I provided him with psychoeducation about common reactions to trauma, many of which he was already familiar from our initial assessment and treatment planning session. I especially focused on normalizing feelings of guilt and shame as well as linking substance use as an understandable coping strategy that had unforeseen negative consequences. Afterward, I provided Bruno with a rationale for doing in vivo exposures and reminded him of the SUDS scale from WET that we would be using again in PE. "Wait, if habituation means I'm supposed to get more comfortable in these situations, why didn't my anxiety go down during the writing sessions?” I validated his concern and also reminded him that his SUDS peaked at 100 and reduced to 75 after the final writing session, which was a downward trend in the direction we would expect, even though he did not habituate much within any particular session. I explained that people progress at different rates and asked if he would be willing to give in vivo exposure a chance to work, to which he agreed.

We set SUDS anchor points, which allowed him to come up with the most accurate SUDS ratings possible. The rest of the session involved constructing his in vivo exposure hierarchy, which featured three types of situations - things Bruno perceived as unsafe based on the belief "the world is completely dangerous," situations that reminded him of the rape, and situations he used to enjoy that he lost interest in after the rape. Bruno's in vivo hierarchy can be seen in Table 4.

When constructing the hierarchy, Bruno had a difficult time differentiating distress levels among hypothetical situations. As such, I continually referred to his anchor points to compare how an exposure target would distress him relative to the predetermined situations. He appeared to become increasingly anxious as we progressively added situations to the hierarchy, fidgeting and sweating profusely. Understandably, he had the most difficulty discussing situations that were trauma reminders, such as deliberately confronting showers, large men, and other stimuli 
associated with rape. "You're sadistic," he snarled at me when I inquired what his SUDS level would be if he were to shower naked at his local YMCA. Again, I validated his concern and reminded him of the rationale for doing in vivo exposure, as well as reminded him that we would be approaching situations gradually and we would not be confronting the top of his hierarchy until he was ready.

I provided Bruno with psychoeducation about how to fill out his exposure records for homework, which included answering "threat forecast" questions about what the worst case scenario was and what his estimation of threat probability was. He agreed to do the first two items on his hierarchy for homework, as well as continue daily breathing practice, share the common reactions to trauma information with his daughters when he spoke to them on the phone, and listen to the recording of the session.

\section{Session 10: Prolonged Exposure Session 3 (90 minutes)}

After Bruno arrived and filled out self-report measures, I checked in with him about homework completion. Unfortunately he "forgot to bring his workbook" and therefore did not have his exposure record with him. I explained that it was virtually impossible to recall SUDS ratings for each exposure accurately from memory and it was thus paramount he brought his workbook to session. When I asked him what he learned from the exposures he did, he said "I think I got lucky that nothing bad happened at the VA.” However, when we processed this it became evident that he only went to the VA one time, whereas he was supposed to repeatedly confront the situation. When we assigned homework for the following session, Bruno agreed that he would go to Walmart at least three times that week.

The majority of the session involved providing rationale for and conducting imaginal exposure for 45 minutes. Bruno voiced understanding of the five key points, which were processing and organizing the memory, allowing him to differentiate between "remembering" and "being re-traumatized," promoting habituation, allowing him to differentiate between the traumatic event and similar events, and to increase his feeling of mastery. We agreed upon a beginning point several minutes "before things got bad" and an ending point "when the danger was over.”

Bruno was reluctant to close his eyes at first, out of fear that "you might do something to me," but was able to after we collaboratively evaluated the evidence for and against me harming him. His initial SUDS rating was 100. When he began revisiting the memory he was using past tense so I paused him and reminded him to describe the experience in present tense as if it were happening right then. He continually had difficulty switching to present tense and abbreviated the memory so significantly that it was nearly impossible to discern what happened at first. For example, during the initial imaginal exposure he said "I went into the shower and then all of a sudden he attacked me and then I was alone on the floor crying.” Additionally, he was talking very quickly and appeared to be affectively constricted, not displaying fear or other intense negative emotions.

Based on these factors, I conceptualized that Bruno was under-engaging, which needed to be addressed; however, given that this was the first imaginal exposure, I did not want to give him 
the impression that he was "doing it wrong." I began asking prompting questions designed to elicit details, such as "What do you see?" and "What are you thinking?" Also, every five minutes I obtained new SUDS ratings, although his SUDS only decreased to 95 by the conclusion of the imaginal exposure. Afterward, we spent 20 minutes processing the imaginal exposure and I praised Bruno for even attempting to access the memory of the rape.

Spontaneously, he said “Doc, I didn’t really get into it today...I was afraid I was going to lose it.” I normalized that concern and encouraged him to more fully delve into the memory the next time. He agreed to listen to the audio recording of the imaginal exposure once a day until our next session.

\section{Sessions 11-13: Prolonged Exposure Sessions 4-6 (90 minutes)}

When Bruno did not show up to his fourth session of PE and did not answer his phone I called his case manager to ensure he was safe. She informed me that "he's been isolating all week" and "barely left the house," which made her suspect he did not engage in many in vivo exposures for homework, although she did not suspect he was experiencing a depressive episode nor did she think he was at risk for self-harm. I consulted with her regarding the resources at the halfway house to determine whether there might be staff available to hold Bruno accountable and help him complete homework. Ultimately, he agreed to involve the behavioral technicians and support staff at the halfway house in his PE treatment because "I need someone to snap me out of my funk when I'm at home.”

Before our rescheduled fourth session of PE, I visited the halfway house and had a brief meeting with the treatment team to provide them with consultation on how to support Bruno through PE and promote treatment compliance. Subsequently, he did a better job of completing in vivo exposures, as evidenced by him bringing his workbook to session and keeping more detailed records.

By the sixth session of PE, he had already tackled the majority of items 1-10 on his hierarchy, the exception being going out on a date, as he had "not been having much luck getting anyone to go out with me.” His threat forecasts gradually included pertinent contextual information; for example, he said that before riding the elevator at the VA the worst case scenario was “a large homosexual OIF Veteran will rape and murder me,” but acknowledged that the odds of this happening were "highly unlikely" due to "the VA elevators being so crowded there would be too many witnesses."

Furthermore, he was beginning to achieve habituation gains both within and between exposure sessions. Notably, his SUDS decreased from 90 to 45 after sitting through the film The Expendables 3 on opening night, and further decreased from 65 to 30 when he saw it again the following day. When discussing homework during the beginning of these sessions, Bruno said "I guess my fears aren't as realistic as I thought...the world is probably safer than I gave it credit for.” He also began to display some mastery, saying "maybe I can handle this stuff okay...I haven’t completely freaked out yet.”

In addition, Bruno began engaging more during the imaginal exposures we conducted 
during session by providing more details and accessing more affect. Several key details in the memory emerged over sessions 4-6 of PE during the imaginal exposure and subsequent processing. For starters, he revealed that he was battling a bad cold at the time of the rape, which "made me weaker than usual” and likely "made it harder to fight him off." Furthermore, he acknowledged that there was a tremendous size differential between them, as the Recruit Chief Petty Officer was approximately 6'4" and weighed approximately 250 pounds, whereas Bruno was 5’10” and weighed 150 pounds at that time.

By putting the memory in context he began to display a shift in cognitions, saying "it probably would have been impossible for me to resist.” In doing so, he noticed himself "beginning to feel less guilty," which he speculated made him "not feel so depressed all the time.” In conjunction, he was experiencing a reduction in SUDS within and between imaginal exposure sessions. For the imaginal exposure during session six of PE, his beginning SUDS was an 80 and his ending SUDS was a 50.

Perhaps the most crucial detail emerged at the end of processing during session six of PE, when I asked Bruno about his persistent feelings of shame. “Doc, there's something I've been leaving out..." he began. Unable to make eye contact, he revealed that he experienced pleasure during the rape and "actually got hard.” Although I provided him with psychoeducation regarding the normalcy of male arousal even in the context of physical abuse, I also suggested that this may constitute the true "hot spot" of the memory, as opposed to the final moments when he was crying on the floor of the shower. "Yeah, I've blocked that part out and tried to pretend it wasn’t real,” Bruno said, agreeing to focus on it during our next imaginal session.

\section{Sessions 14-15: Prolonged Exposure Sessions 7-8 (90 minutes)}

For homework before and between these sessions, Bruno began tackling in vivo exposures that were trauma reminders, such as showering with the door unlocked and volunteering at a rape crisis center phone hotline. He noticed that his SUDS were consistently higher at the beginning of each in vivo exposure than they were listed on his hierarchy, which he theorized was due to "not realizing how hard these things would be because I've avoided them so long." For example, when he showered with the door unlocked his initial SUDS rating was 100 despite it being ranked as an 80 on his hierarchy. However, remaining in these situations allowed him to realize that "I’ll calm down eventually" and "I can handle being uncomfortable."

During the imaginal exposures, Bruno was able to focus on the moment when he began to experience physiological stimulation in spite of extremely high SUDS (initial ratings were 100 and 95 respectively during these two sessions). And yet, by the end of the imaginal exposure in session eight of PE his SUDS rating was down to 45. At first in processing he questioned his sexuality and wondered whether there was something "defective” about him, but he ultimately reached the conclusion that "I had no control over getting hard just like I had no control over the entire thing." Based on him completing nearly everything on his in vivo exposure hierarchy, the significant reduction in SUDS during in vivo and imaginal exposures, as well as reductions in scores on self-report measures of PTSD and depressive symptoms, Bruno and I agreed that the next session would be his final session of PE. (see Tables 1 and 2 for final scores) 


\section{Session 16: Prolonged Exposure Session 9 (90 minutes)}

After filling out his final PCL-5 and BDI-II, Bruno proudly showed me that he completed every item on his in vivo exposure hierarchy, including the final item of showering naked at the YMCA, which he said he was "terrified of” but "realized I can handle it now." Similarly, when he finished his final imaginal exposure and processed it he stated "I know I can live my life without being afraid and without drinking to take the pain away.”

One of the most important tasks of the final session was Bruno re-rating his SUDS scores for each item on his in vivo hierarchy (see Table 3 for final scores). Not only did every item decrease in SUDS, some items had dramatic decreases. In processing our termination, he shared his thoughts about our work ending, what it was like to share his trauma with me, and whether he had any concerns about maintaining his gains. "I'm definitely anxious about falling into the avoidance trap and using again but I'm going to give it my best shot.

Remember that woman from OkCupid I went out with? She's meeting my daughters next week," he said happily. I wished him well and reminded him that he was welcome to return to our program should he ever experience difficulties related to his trauma in the future. I also asked if he would be willing to provide me with some qualitative feedback on the stepped-care model of treatment, specifically whether he would have engaged in Prolonged Exposure had he not first completed Written Exposure Therapy. "I'm not sure," he said. "I think it was helpful to do the writing first because it desensitized me to the memory. I may have freaked out if I started PE right away.”

\section{C. CHARLES' ASSESSMENT: PRESENTING PROBLEMS, GOALS, STRENGTHS, AND HISTORY}

\section{Presenting Problems}

Charles presented for treatment to "find someone to listen to me." He reported that he had received multiple courses of supportive psychotherapy at his local VA hospital and community Vet Center over "the past few decades.” However, when his Vet Center therapist recently retired he was referred for treatment to this clinic. He spoke of having "haunting dreams," which made him afraid of falling asleep. He also reported having "self-destructive urges” and occasionally engaged in "reckless" behaviors. In addition, he considered himself "alienated from society."

According to Charles, his difficulties began after he witnessed his best friend in the Marines commit suicide by gunshot wound to the head. Afterward, his symptoms were exacerbated when he experienced racism from the rest of his battalion when he sought support for feelings of guilt and depression, as he blamed himself for his friend's death. Since then, Charles has also suffered the loss of his wife due to breast cancer and so he wanted "help dealing with all these abandonments...my friend, my wife, my therapist, it's enough already!" Although he knew that he "needs to stop avoiding everything," he "doesn't know how to cope” and "just feels lonely all the time." 


\section{Assessment and Diagnosis}

During the initial assessment session, I conducted an unstructured clinical interview with Charles and also administered the same measures that Alex and Bruno received during their initial assessment sessions. These included the CAPS-5, PCL-5, BDI-II and LEC-5. The PCL-5 and BDI-II functioned as the treatment's outcome measures, so Charles filled them out at the beginning of each subsequent session. The initial scores on each of the measures are presented in Tables 1 and 2. Results of his outcome measures were discussed throughout the course of therapy and helped guide treatment.

When filling out the LEC-5, Charles identified "too many stressful events." In addition to his friend's suicide, he reported multiple stressors during Vietnam, which were consistent with DSM-5 Criterion A stressor requirements. However, for the purposes of the clinical interview, he was assessed for symptoms of PTSD in relation to his friend's suicide, as "that's the one that hurts the most.

Charles reported having "terrible nightmares" of his friend's death "a few times a week." This met criteria for one past month intrusion symptom of severe severity (i.e., coded as 3 on a 0-4 scale) and thus met Criterion B. He also reported avoiding thoughts of the trauma (i.e. pushing thoughts out of his mind) "all the time," as well as avoiding weapons (e.g., stays away from police) "as much as possible," which met criteria for past month markedly elevated avoidance symptoms (i.e., coded as 3) and thus met Criterion C. In addition, he reported thinking that "it's all my fault" after his friend committed suicide has felt consistently guilty since then, as well as "usually feeling detached from everyone." This met criteria for two past month negative alterations in cognitions and mood symptoms of extreme severity (i.e., coded as and thus met Criterion D. He also reported having occasional "reckless moments” (e.g., driving $100 \mathrm{mph}$ ) as well as frequent insomnia which met criteria for two past month markedly elevated alterations in arousal and reactivity (i.e. coded as 3) and thus met Criterion E. Charles' symptoms have persisted for more than one month (i.e., Criterion F), have caused him significant social impairment (i.e., Criterion G), and were not due to medication/substances (i.e., Criterion H). He thus met full criteria for Posttraumatic Stress Disorder (changes in his diagnoses can be seen in Table 3).

The PCL-5 was administered to assess Charles’ PTSD symptoms and his PCL-5 score was a 48 at the start of treatment, indicating he was experiencing mild PTSD symptoms. Fluctuations in his PCL-5 scores can be seen in Table 1. The BDI-II was administered to assess his depressive symptoms and Charles’ BDI-II score was a 16 during the initial assessment, indicating that he was experiencing mild symptoms of depression. Based on this, he was assessed for the presence of depressive disorders and bipolar and related disorders; when he did not meet criteria for any of these disorders, his depressive symptoms were conceptualized as secondary to his PTSD symptoms (i.e., it was hypothesized that by alleviating PTSD symptoms the depression would remit on its own). Fluctuations in his BDI-II scores can be seen in Table 2. 


\section{Relevant History}

Charles was born and raised in a low-income section of a mid-Atlantic city by his biological mother, as the youngest of four children. His parents were unmarried and he never met his father. When he was fourteen, his mother died of a heroin overdose and he was sent to live with his grandparents. He reported growing up in "a chaotic environment," where his mother "dated many men" and "drugs were everywhere." As a result, Charles "swore off substances" and excelled athletically and received a scholarship to play football at a large public university near where he grew up. Unfortunately, he injured his knee during his senior year and was thus unable to play football professionally.

After completing his undergraduate studies, he married his college sweetheart and decided to pursue graduate school in kinesiology, hoping to become a football coach. However, he was drafted into the United States Marine Corps in December of 1969, and was denied a deferment despite him being a graduate student. He found this "extremely unfair" and wondered whether it was "because I was black."

Charles received basic training at Parris Island Recruit Depot in South Carolina for eight weeks and Infantry Training Regiment for four weeks before being sent to the Quang Nam province of Vietnam in March of 1970 , where he joined the $1^{\text {st }}$ Marine Division, $5^{\text {th }}$ Marine Regiment. His MOS was 0311 Rifleman. His primary responsibilities included "gruntwork” and going out on patrols.

He reported that after a particularly tough clear and search operation during the summer of 1970, he witnessed his best friend die by a self-inflicted gunshot wound to the head. Charles "had a difficult time coping” afterward, which was exacerbated by a perceived lack of support from the other Marines. "They acted like there was something wrong with me, especially the white guys,” he said. “They started messing with me” by playing “mean-spirited practical jokes.” This behavior reportedly persisted throughout the rest of his tour in Vietnam, which ended in April 1971 when he returned home to Camp Pendleton. Charles served his remaining period of enlistment in the Marines and was honorably discharged at the rank of Corporal (E-4).

When Charles retired from the Marines in 1973 he and his wife moved to a small suburb of a large northeastern city. After years of trying to have children, they learned that they were unable to conceive; for several years thereafter they considered adopting but ultimately did not. In the meantime, he began working for the United States Postal Service as a mail carrier to “provide my family with some stability,” having little success landing jobs in athletics.

However, he frequently changed positions within the USPS for "getting into conflicts" with co- workers, eventually settling into a mail processing clerk job, which he held until he retired in 2005.

Shortly thereafter, Charles' wife became sick and lost a long battle with breast cancer in 2010, which was “devastating” to him. "I miss her every day,” he said. However, he also acknowledged often "fighting like cats and dogs" with her and characterized their marriage has "somewhat rocky." Since then, he got a service dog for companionship and has been active in 
Veteran support groups and auto-racing clubs, although he does not "hang out with the guys" outside of group.

\section{Goals and Strengths}

Charles presented with notable strengths. He was intelligent and he involved himself in activities (e.g. racing club) despite his PTSD. Although he stated that he was invested in working on reducing his PTSD symptoms, he believed that supportive treatment would accomplish this. "I just want someone to listen to me," he said. "Sometimes there's stuff I need to get off my chest." When I explained to Charles that exposure-based treatments have better evidence than supportive treatments in fighting PTSD, he reluctantly agreed to "give it a try."

\section{C. CHARLES' CASE FORMULATION AND TREATMENT PLAN}

\section{Formulation}

When Charles witnessed his friend's suicide, he subsequently developed a fear network in memory, which is a structure containing information about stimuli, responses, and meanings associated with the event. Through classical conditioning, the traumatic event (i.e., the suicide), an unconditioned stimulus, became associated with conditioned stimuli (e.g., guns), which began eliciting conditioned fear responses (e.g., increased heart rate, sweating). Whenever Charles was reminded of the suicide via external or internal reminders, he had experienced physiological symptoms (i.e., fight or flight) designed to elicit escape and avoidance behavior, which he had consistently performed. In addition, Charles experienced intense feelings of guilt whenever meanings (e.g., "It’s my fault," "I should have helped him”) within the fear network were activated.

Charles’ fear network became pathological because its associations among stimuli no longer represented the world accurately (i.e. not every gun means someone is going to commit suicide), although he continued to avoid. In doing so, Charles had unknowingly developed and maintained PTSD because avoidance had prevented him from engaging in corrective emotional learning. Charles likely developed negative beliefs about himself and the world (e.g., "I am to blame for the event," "People will abandon me," and "Don't get close to anyone"). By avoiding situations that could disconfirm these beliefs (e.g., making new friends), Charles has continued to suffer from PTSD. Charles' depression likely developed and was subsequently maintained by a loss of positive reinforcement opportunities (stemming from isolation) and maladaptive cognitions (e.g., "It's my fault”).

\section{Treatment Plan and List of Treatment Goals}

Goal 1: Provide rationale for treatment, establish rapport, and create a safe/validating therapeutic environment.

Because Written Exposure Therapy is designed with little therapist-client contact in mind, it was especially important to build rapport during the initial assessment session. As 
Charles had some ambivalence about exposure-based treatments, I wanted to create a safe space where he felt comfortable enough to discuss his trauma and associated symptoms. I also wanted to provide him with information regarding the empirical support for both Written Exposure Therapy and Prolonged Exposure, as well as discuss the similarities and differences between the treatments and explain the rationale for engaging in Stepped Care for PTSD.

Goal 2: To decrease Charles’ PTSD symptoms to a PCL-5 score below the suggested cutoff for PTSD $(<38)$.

Written Exposure Therapy is hypothesized to work by blocking avoidance of the traumatic memory through repeated written exposures to it, which facilitates emotional processing and habituation of conditioned negative emotional responses, thus reducing PTSD symptom intensity. Charles' initial PCL-5 score of 48 would need to drop at least 10 points for him to no longer meet criteria for PTSD. If Charles' PTSD symptoms do not improve after he completes WET, he will be given the option of stepping up to Prolonged Exposure, which is hypothesized to reduce PTSD symptoms through imaginal and in vivo exposures.

Goal 3: To increase Charles’ mastery over confronting the trauma memory and feared situations by reducing avoidance

If Charles chooses to engage in Prolonged Exposure therapy, he will learn about subjective units of distress ratings in order to generate an in vivo exposure hierarchy, featuring increasingly challenging situations that remind him of the suicide as well as behavioral activation-based situations he may also be avoiding (e.g., making new friends). He will also engage in imaginal exposures to the memory of the suicide and process the exposure experience with nondirective statements (e.g., education about trauma reactions, paraphrasing, reiterating the treatment rationale, and normalizing reactions). To help accomplish this goal, Charles will complete daily homework of listening to a recording of his imaginal exposure as well as completing in vivo exposures each day.

\section{C. CHARLES' COURSE OF TREATMENT}

\section{Session 1: Assessment, Treatment Planning, Establishing Rapport (3 hours)}

Several weeks before meeting with Charles for the first time, his therapist at the local Vet Center contacted me to inquire about the program at our clinic. She stated that she was retiring soon and hoped to transfer a client of hers to our program. She described a Veteran whom she thought could benefit from evidence-based PTSD treatment and whom she thought needed a "change of scenery." She surmised that the Veteran had resigned himself to "venting about the crisis of the week" and was concerned about transferring him to another provider at the Vet Center because "he won't get EBPs here."

I told her that we would welcome the referral as long as the Veteran understood that we specialized in providing brief, evidence-based, trauma-focused treatments and would not be able to offer supportive psychotherapy. After Charles was authorized for free treatment, I called him to schedule an initial assessment session. "Why do I need an assessment? We both know I have 
PTSD,” he grumbled. I explained that our program requires an initial assessment prior to initiating treatment based on the rationale that symptoms can change over time. Charles sounded puzzled but nonetheless consented to meet with me.

When I greeted Charles in the waiting room, I immediately noticed a large golden retriever wagging its tail and slobbering on the carpet. "You must be Charles...but I'm not quite sure who you are,” I said smiling, looking at the dog. "That’s Buddy," he replied. "He’s my service animal.” I explained confidentiality and its limits and obtained Charles' informed consent to me audio-recording the assessment for supervision purposes, clarifying my role as a psychology trainee. I created an agenda for the session by explaining the different assessment tasks it would be helpful for him to complete, and set aside time for treatment planning informed by the assessment results. He asked if we could add "discussing benefits" to the agenda and said he wanted to know if the results of this assessment would impact his disability rating, as he was $50 \%$ service-connected for PTSD. I explained that we were not affiliated in any way with the Veterans Benefits Administration but that the results of our assessment would become part of his Veterans Health Administration medical record, which may be requested by the VBA as part of their Compensation \& Pension examinations. I indicated that it was possible the VBA may reduce his service connection for PTSD if he no longer met diagnostic criteria for PTSD. Although Charles appeared unnerved by that, he agreed to proceed.

I began the assessment by having Charles fill out self-report measures (i.e., PCL-5, BDIII), which I followed up with an unstructured interview to ask additional diagnostic questions and obtain relevant information across life domains. He occasionally appeared distracted when he would pet Buddy and refilled his water bowl but was otherwise cooperative throughout the interview. I concluded the assessment part of the session by administering the LEC-5 and CAPS5, after which I gave him a brief break so I could score the assessment measures.

I explained that he met criteria for Posttraumatic Stress Disorder and that his depressive symptoms appeared to be secondary to PTSD. I provided him with psychoeducation about PTSD etiology and prognosis, the evidence base regarding PTSD treatments, and his treatment options, briefly describing Prolonged Exposure and Cognitive Processing Therapy, as well as novel treatments such as Written Exposure Therapy and Virtual Reality Exposure Therapy.

Charles expressed uncertainty about these treatment options. "But doc, sometimes I get pissed off about stuff, like the government, or if someone cuts me off when I'm driving, and I like to come in and get it off my chest. If we keep focusing on what happened in Vietnam how will we have time for everything else?”

I validated his concerns and reminded him that he could return to supportive psychotherapy after engaging in these treatments if he wished. We collaborated on the goals of working together to reduce his PTSD symptoms and he reluctantly agreed to engage in a stepped-care treatment where the initial step was Written Exposure Therapy with the option of "stepping-up" to Prolonged Exposure. We scheduled the initial therapy session for the following week. However, as he was leaving he said, "You know what, doc? I'm just not sure this is for me...I'm going to think it over and let you know." 


\section{Session 2: Written Exposure Therapy Session 1 (60 minutes)}

By the time of our "scheduled session” I still hadn't heard from Charles so I called and left him a voicemail to ascertain whether he was still interested in treatment. Approximately one week later, he returned my call and agreed to begin treatment, having "realized I need someone to talk to.”

He arrived on time for the session and filled out self-report measures (i.e., PCL-5, BDIII). After bringing him into the therapy room and quickly checking his response to item 9 on the BDI-II to ensure he was not endorsing any suicidal ideation, I informed him that we would begin Written Exposure Therapy today. The first twenty-five minutes of the session involved me reeducating him about the symptoms of PTSD and reminding him of the rationale for written exposure. We discussed how he experienced changes in his physical reactions, emotions, thoughts, and behaviors in response to the suicide. "It made me not want to get close to anyone except my wife," he said. "I like being around people to keep my mind off things but I won't actually call anyone a friend. That's also why I got Buddy - for companionship. Animals are much more loyal than people."

As per the treatment manual, we explored the consequences of Charles' avoidance. I provided him with psychoeducation regarding how to measure his anxiety level using subjective units of distress (SUDS), which is a 0-100 scale where $0=$ no anxiety and $100=$ the most anxiety he has ever felt. I normalized that he may experience his highest SUDS level during the initial writing session but his anxiety would likely decrease by the final writing session.

At that point, I gave Charles the writing instructions, which included general directions for all of the writing sessions as well as specific instructions for the first session. I informed him that I would like him to write about witnessing his best friend die by a self-inflicted gunshot wound to the head without worrying about spelling or grammar, in as much detail as possible, for 30 minutes without stopping. He was instructed to include details on how the suicide happened, the involvement of other people, what he was feeling and thinking as the trauma was happening, and his very deepest emotions and thoughts about it now. For the first writing session, Charles was instructed to start at the beginning of the memory and was encouraged to include sensory details, and include the thoughts and feelings he experienced during and immediately after the trauma. He was also reminded that the trauma was not actually happening again, but he was simply recounting it. Finally, he was instructed to provide SUDS ratings before he started writing and after he had finished.

I let Charles know that I would be leaving the therapy room to give him privacy while he wrote and that I would return in 30 minutes; if, in the meantime, he had any difficulties he could find me in the adjacent room. I also let him know that I would be briefly checking his writing to confirm that he had written about the suicide, but it would be up to him whether he wanted to me to read the entire essay in detail. Charles didn’t have any questions and so I left the room and set a 30 minute alarm to keep track of the time. 
When I returned, he had completed the writing assignment, however the writing did not include any contextual details of the suicide itself. Rather, he had written about his difficulties after the suicide occurred, especially the feelings of loneliness and sense of isolation he experienced. I praised him for completing the assignment and also encouraged him to focus on the trauma directly as opposed to its aftermath. His pre-SUDS rating was an 80 and his postSUDS rating was 90. I inquired whether he experienced any difficulties during the writing session, especially given the increase in SUDS, and he said “I don't want to go back there. Can't I just let sleeping dogs lie, so to speak?” I normalized his feelings, as well as the likelihood that he would experience thoughts and feelings related to the trauma during his week; he was instructed not to avoid these thoughts and feelings when they arose, but rather to allow them to be present.

\section{Sessions 3-6: Written Exposure Therapy Sessions 2-5 (45 minutes)}

Although Charles was cooperative in arriving to these sessions on time and filling out the PCL-5 and BDI-II in the waiting room, he repeatedly had difficulty writing about the trauma directly. In each of these sessions I reminded him that we don't want to reinforce avoidance and speculated whether his insistence to write about the trauma's impact primarily functioned as a way to avoid processing the memory itself. For example, in session 2 of WET he wrote about how the loss of his friend made it difficult for him to tolerate other losses (e.g., his wife's death, his therapist retiring). In session 3 of WET, he wrote about how the loss of his friend makes him not want to be around weapons and how he believes strongly in gun-control reform. In session 4 of WET, he wrote about how the men in his unit did not support him afterward and engaged in racist behaviors toward him.

I attempted to engage him in a discussion of our diversity and how it was for him to be working with a white therapist, hoping it may increase rapport and allow him to feel more heard. However, he did not appear to be comfortable having that conversation and opted to leave the session.

Throughout, it was somewhat unclear whether Charles was definitively avoiding writing about the trauma directly or whether he had comprehension difficulties and legitimately thought he was doing what he was asked. "I'm not doing it right?" he wondered aloud when asked about this at the end of session 2. "This is what's bothering me doc, so I'm writing about it." It appeared as if Charles had immediately skipped ahead to writing about the way the trauma had impacted his life. However, because he never wrote about the memory directly we were unable to be faithful to the protocol in focusing on the most distressing aspect of the memory. In addition, it did not seem that he was habituating based on atypical SUDS ratings. He consistently had higher SUDS ratings at the end of the writing sessions than when he began and he did not habituate between sessions. At the end of session 5 of WET, I explained that I would like Charles to come in the following week for a treatment planning session to discuss the next steps in his care.

\section{Session 7: Treatment Planning (90 minutes)}

After Charles filled out self-report measures, I provided him with his PCL-5 and BDI-II 
scores over the course of WET; his PCL-5 dropped from a 48 to a 37 and his BDI-II dropped from a 16 to a 15. I explained to him that his PCL-5 score suggested that he no longer met full diagnostic criteria for PTSD and could be referred back to the Vet Center for supportive treatment if he wished. “That's not possible” he said. “I don't feel any better and I don't want a referral...I'm sick of bouncing around.”

I went item by item and inquired about Charles' responses. He revealed that he "doesn't take it seriously" and "barely pays attention" as he fills the measures out. When we discussed this, he reported that he "just wanted someone to talk to" and stated he had grown frustrated "not having an outlet" so he chose to use the writing sessions "to vent." I reminded Charles that research has shown that trauma-focused treatments have the greatest efficacy in treating PTSD and reminded him that, to use his own language, he wasn't feeling better. I also reminded him that he was free to leave our program and receive supportive therapy elsewhere. Charles shook his head and banged his fist on the desk. "No! I just want to stay in one place."

Based on his verbal report of non-improvement and his admission of invalid selfreporting, I suggested that he continue in therapy and begin Prolonged Exposure. I hypothesized that engaging in imaginal exposures to the memory of the suicide would reduce the intrusions he was experiencing. I also hypothesized that engaging in in vivo exposures to situations where he may encounter weapons and engaging in behavioral activation exposures involving other people would overall decrease the sense of isolation he was experiencing.

Although Charles agreed to begin PE, I questioned whether he would be more compliant with filling out self-report measures validly and engaging in the treatment the way it was designed. "You drive a hard bargain, doc," he said. I had him fill out an additional self-report inventory assessing his satisfaction with the treatment (CSQ-8). He reported being very satisfied with Written Exposure Therapy and said, "It gave me a way to talk about my problems when you didn't want to listen." He stated that he planned on getting a journal because he "enjoyed writing so much.”

\section{Session 8: Prolonged Exposure Session 1 (90 minutes)}

I called Charles before our eighth session and first session of PE to remind him to bring an audio recording device so he could record the session. I also let him know that the DoD/VA created a smartphone app called "PE Coach" that features a recording device built in. He said he would download the app and use his smartphone. When he arrived, I provided him with the treatment rationale and presented him with an overview of PE's structure.

Instead of doing the complete trauma interview, which would have been redundant based on the assessment he already completed, I only asked questions which filled in any missing gaps and offered him the opportunity to share any additional details about the suicide, which he declined. Afterward, we practiced breathing retraining for 15 minutes and he identified situations where he tends to hyperventilate and it would be beneficial to use relaxation skills. 
Charles appeared to enjoy the breathing exercises and said he would practice them throughout the week. Given his questionable motivation thus far, I did not once use the term "homework" and instead recommend that he "engage in some helpful activities" between sessions 1 and 2, which were to use deep breathing three times a day for 10 minutes each time, to listen to the recording of the session once, and to read the rationale for treatment in his workbook.

\section{Session 9: Prolonged Exposure Session 2 (90 minutes)}

After Charles arrived and filled out self-report measures, I checked in with him about "how practice went." He said he "did everything I was supposed to," and we set an agenda for the session. Charles stated that he "wanted to talk about an issue he had yesterday" but declined to elaborate, saying "we'll get to it after you do your thing." During the first part of the session I provided him with psychoeducation about common reactions to trauma, many of which he was already familiar from our initial assessment and treatment planning session. I especially focused on normalizing feelings of guilt and having a sense of isolation. Afterward, I provided Charles with a rationale for doing in vivo exposures and reminded him of the SUDS scale from WET that we would be using again in PE. We set SUDS anchor points to come up with the most accurate SUDS ratings possible. Charles' anchor points were: $0=$ "being alone in my house petting Buddy," 25 = "asking my wife out on a date for the first time," 50 = "finding out my therapist was retiring," 75 = "getting drafted to go to Vietnam,” 100 = "watching my friend commit suicide."

However, when I attempted to begin constructing his in vivo exposure hierarchy, he protested. "Doc, I really don't see the point in this. Why would I deliberately put myself into an uncomfortable situation? I get into enough of those already!” I reminded Charles that he had agreed to engage in PE during our treatment planning session with the rationale that it would be helpful based on his goal of reducing PTSD symptoms. I asked him whether not constructing a hierarchy possibly functioned as avoidance behavior for him. "You tell me, doc," he replied. At that moment, my countertransference was extreme frustration. Although I understood his reluctance to return to the Vet Center based on not wanting to start over again with a new therapist, it seemed that he did not want to follow treatment recommendations in our program; I shared these thoughts with him.

"Hey doc, I'm starting to get a headache...is it okay if we call it a day and pick up here next week?” We agreed to resume session 2 of PE the following week. Unfortunately, Charles did not show up that day and did not return voicemails I left him. After the second voicemail, I sent a letter informing him that if he did not contact me within two weeks I would assume he was no longer interested in treatment. When that date occurred, I closed his file. 


\section{THERAPY MONITORING AND USE OF FEEDBACK INFORMATION}

For the duration of Alex's, Bruno's, and Charles' treatments, I received individual supervision from a licensed clinical psychologist. Before our supervision meetings, my supervisor would review the audio recordings of my session with these Veterans and we discussed key points during supervision. Our supervision was extremely collaborative and my supervisor managed to both challenge and support me a psychology trainee. Additionally, I was provided with group supervision among other psychology trainees, which was helpful in offering me additional perspectives. Finally, during the course of my work with these Veterans, I attended a weekly process group for all mental health staff delivering trauma-focused treatments. The combination of individual and group supervision provided me with valuable feedback during my work with Alex, Bruno, and Charles and the process group provided me with self-care. I am fortunate for the resources provided to me throughout the duration of their treatments

Alex’s, Bruno's, and Charles' treatments were continuously assessed via two quantitative self-report outcome measures: the Beck Depression Inventory - Second Version (BDI-II) and the PTSD Checklist for DSM-5 (PCL-5). The Veterans completed each of these measures directly before our therapy sessions on a weekly basis. These measures provided me and my supervisor with ongoing feedback, and helped us ascertain how the Veterans were progressing through the treatments. At times when Alex, Bruno, and Charles may not have felt like their symptoms were improving, it was helpful to provide them with objective data in response to their claims. In addition, the Veterans' satisfaction with Written Exposure Therapy was assessed by a quantitative self-report outcome measure: the Client Satisfaction Questionnaire-8 (CSQ-8).

\section{CONCLUDING EVALUATION OF THE THERAPY'S PROCESS AND OUTCOME}

\section{The Outcome of Alex's, Bruno's, and Charles' Therapy}

The quantitative and qualitative data (see below) from Alex's and Bruno's cases indicate a favorable treatment outcome, whereas Charles' data reflects a somewhat more unfavorable outcome. Alex's and Bruno's ability to engage in treatment despite substantial discomfort allowed them to make significant therapeutic gains by treatment termination. In contrast, Charles’ failure to engage prevented him from achieving maximum therapeutic benefit.

\section{Quantitative Results for All Three Clients}

Table 1 presents Alex’s, Bruno's, and Charles’ PCL-5 scores. Of note, the PCL-5 is a relatively new measure that is just beginning to receive sufficient scholarly attention to provide us with reliability statistics. Also, due to DSM-5 changes in PTSD symptom criteria, the PCL-5 scores are incompatible with PCL for DSM-IV scores. Although we cannot yet use Jacobson and Truax’s (1991) Reliable Change Index for the Veterans’ PCL-5 data, we can unofficially estimate whether any changes observed would reach clinical significance based on the PCL for DSM-IV data. As Weathers and colleagues note (2013), the expectation is that the PCL-5 
reliability data will be similar to the PCL for DSM-IV data. Thus, a 5-10 point change represents reliable change (i.e., change not due to chance) and a 10-20 point change represents clinically significant change. They recommended using 5 points as a minimum threshold for determining whether an individual has responded to treatment and 10 points as a minimum threshold for determining whether the improvement is clinically meaningful.

Alex's PCL-5 score was a 60 at the start of treatment, indicating he was experiencing substantial PTSD symptoms, and was a 40 at the end of treatment, indicating he was experiencing mild PTSD symptoms, slightly above the recommended cutoff. The 20 point score reduction would likely represent a clinically meaningful change.

Bruno's PCL-5 score was a 72 at the start of treatment, indicating he was experiencing significant PTSD symptoms, and was a 36 at the end of treatment, indicating he was also just below the recommended cutoff. The 36 point score reduction would also likely represent a clinically meaningful change.

Charles' PCL-5 scores was a 48 at the start of treatment, indicating he was experiencing moderate PTSD symptoms, and was a 45 at the end of treatment, indicating he was still experiencing moderate PTSD symptoms. However, the 3 point score reduction would not likely represent a clinically meaningful change.

Table 2 presents Alex’s, Bruno’s, and Charles’ BDI-II scores. Alex’s initial scores were indicative of mild depressive symptoms (as categorized by scores of 14-19, inclusive, on the BDI-II). Over the course of treatment, his BDI-II scores briefly increased to the moderate depressive symptom range (as categorized by scores of 20-28, inclusive, on the BDI-II) before returning to the minimal depressive symptom range.

Bruno’s initial scores were indicative of moderate depressive symptoms and fluctuated over the course of treatment; they decreased to the mild depressive symptom range, then returned to the moderate depressive symptom range, before ultimately returning to the mild depressive symptom range.

Charles' initial scores were indicative of mild depressive symptoms. Over the course of treatment, his scores fluctuated from the minimal depressive symptom range (as categorized by scores of $0-13$, inclusive, on the BDI-II) to the moderate depressive symptom range before eventually settling in the mild depressive symptom range. For Alex and Bruno, their scores decreased to a clinically significant degree, as measured by the Reliable Change Index.

Given the newness of Written Exposure Therapy, Sloan and colleagues (2012, 2013) examined levels of satisfaction with the treatment using the Client Satisfaction Questionnaire-8. Scores range from 8 to 32, with higher values indicating higher satisfaction. In the first published study on WET (Sloan et al., 2012), the CSQ-8 mean was 28.20 (SD = 3.3; range = 2132), suggesting that the participants had a high level of satisfaction with the treatment. In the second published study (Sloan et al., 2013), the CSQ-8 mean was 30.00 (SD = 2.6; range = 2532), again suggesting that participants had a high level of satisfaction with the treatment. Alex, Bruno, and Charles all filled out the CSQ-8 during their treatment planning session after they 
completed WET. Alex’s, Bruno's, and Charles' CSQ-8 scores were 29, 30, and 31 respectively $(M=30.00, S D=1.0$, range $=29-31)$, reflecting high levels of satisfaction with the treatment.

\section{Qualitative Results-Alex}

As described in sections 6A, 6B, and 6C (Courses of Treatment), Alex, Bruno, and Charles, and I reviewed their treatment gains during the treatment planning session after they completed WET as well as during their final two sessions of PE (if applicable). The following reflects a summary of the qualitative results of Alex's treatment outcome:

- $\quad$ Alex was experiencing reduced symptoms of PTSD and depression that included fewer intrusions, improved concentration, and a shift in his thinking away from blaming himself for the IED blast.

- $\quad$ Alex appeared to experience increased comfort and rapport with me over the course of our work together. He initially used sarcasm and tried to write from home as avoidance strategies to prevent him from connecting with me. However, by the time we concluded WET he seemed to present more genuinely.

- $\quad$ Alex's marital functioning had improved considerably and he appeared motivated to continue working on his marriage. His wife agreed, "He's doing a lot better, even if he doesn't see it all the time.”

- $\quad$ Alex obtained valuable psychoeducation about the factors maintaining his PTSD, as evidenced by him saying that he knows "avoidance is the enemy." He displayed mastery in combating avoidance by sticking with the treatment and being "glad” he did.

- $\quad$ At the end of treatment, Alex continued to avoid driving and his wife accommodated his behavior by giving him rides. However, he appeared to have understanding that he could work on this if he decided to seek treatment (i.e. Prolonged Exposure) in the future.

\section{Results in Context of Original Treatment Plan-Alex}

Based upon the quantitative and qualitative results listed above, it appears that Alex was somewhat successful in meeting the treatment goals that were described in Chapter 5A (Case Formulation and Treatment Plan):

GOAL 1: Provide rationale for treatment, establish rapport, and create a safe/validating therapeutic environment.

GOAL 2: To decrease Alex's PTSD symptoms to a PCL-5 score below the suggested cutoff for PTSD (<38).

GOAL 3: To increase Alex's mastery over confronting the trauma memory and feared situations by reducing avoidance 
In summary, Alex experienced many changes over the course of our treatment together. His PTSD and depressive symptoms decreased, his marriage was improved, and he demonstrated increased mastery over and received education regarding avoidance. Although he did not achieve all his treatment goals, he had a positive therapy experience that may increase the likelihood he will reengage in the future.

\section{Qualitative Results-Bruno}

The following reflects a summary of the qualitative results of Bruno’s treatment outcome:

- $\quad$ Bruno was experiencing reduced symptoms of PTSD and depression that included fewer intrusions, decreased hypervigilance, reduced feelings of shame, and a shift in his thinking away from blaming himself for the rape.

- $\quad$ Bruno demonstrated reduced avoidance of thoughts and feelings related to the rape, as well as reduced avoidance of situations that reminded him of the rape, seemed generally dangerous, and were behaviorally inhibited. He conquered every item on his in vivo exposure hierarchy.

- $\quad$ Bruno obtained valuable psychoeducation about the factors maintaining his PTSD and displayed mastery in combating these factors. In processing the imaginal exposures, he gained access to valuable contextual details that allowed him to think more flexibly about the rape. By doing imaginal and in vivo exposures, he experienced habituation, which taught him that his anxiety would eventually go down and he could handle tough situations. He also exhibited extinction learning where some reminders of the rape no longer elicited fear. Overall, his cognitions shifted from "the world is dangerous and I am incompetent" to "the world is not as dangerous as I thought and I am more capable than I thought.”

- $\quad$ Bruno appeared to experience increased comfort and rapport with me over the course of our work together which began generalizing to other people. He initially was terrified of me as a male therapist (i.e., not even wanting to be in the room with me) and by the end of treatment was able to have large men spot him at the gym. He met a woman off an internet dating website and planned on introducing her to his daughters.

- $\quad$ Bruno did not relapse during our work together. Although he was living in a controlled environment, it is notable that he had the emotion regulation and distress tolerance skills to tolerate these treatments without using alcohol to numb the pain.

\section{Results in Context of Original Treatment Plan-Bruno}

Based upon the quantitative and qualitative results listed above, it appears that Bruno was very successful in meeting the treatment goals that were described in Chapter V-B (Case Formulation and Treatment Plan):

GOAL 1: Provide rationale for treatment, establish rapport, and create a safe/validating therapeutic environment. 
GOAL 2: To decrease Bruno's PTSD symptoms to a PCL-5 score below the suggested cutoff for PTSD (<38).

GOAL 3: To increase Bruno's mastery over confronting the trauma memory and feared situations by reducing avoidance

Bruno achieved a radical transformation over the course of his treatment. His PTSD and depressive symptoms decreased, his social network increased, and he maintained sobriety while doing difficult therapeutic work. He achieved all his treatment goals and appeared more hopeful about his future.

\section{Qualitative Results-Charles}

The following reflects a summary of the qualitative results of Charles' treatment outcome:

- $\quad$ Charles did not exhibit clinically significant reductions in PTSD or depression symptoms, although it was difficult to discern his true distress levels based on his acknowledged carelessness while filing out measures. Regardless, he did not appear to have an adverse reaction to the treatments.

- $\quad$ Unfortunately, Charles continued to display prominent avoidance behavior throughout treatment. He had difficulty writing directly about witnessing his friend's suicide in Vietnam. He also avoided constructing an in vivo hierarchy during Prolonged Exposure. Finally, he dropped out of treatment without contacting me to explain his decision.

- $\quad$ Although Charles obtained valuable psychoeducation about the factors maintaining his PTSD, he failed to display mastery in combating these factors. He seemed to think that supportive treatment would somehow cure his PTSD, despite the available evidence to the contrary. Although he consented to do trauma-focused treatment, it appeared that he was ambivalent about being referred and may have resented his old therapist for retiring.

\section{Results in Context of Original Treatment Plan-Charles}

Based upon the quantitative and qualitative results listed above, it appears that Charles was unsuccessful in meeting the treatment goals that were described in Chapter V-C (Case Formulation and Treatment Plan):

GOAL 1: Provide rationale for treatment, establish rapport, and create a safe/validating therapeutic environment.

GOAL 2: To decrease Charles' PTSD symptoms to a PCL-5 score below the suggested cutoff for PTSD $(<38)$.

GOAL 3: To increase Charles' mastery over confronting the trauma memory and feared situations by reducing avoidance 
Overall, Charles failed to engage in treatment and thus did not achieve the expected benefits from participating. It is possible that I never truly achieved goal 1 with him, which likely prohibited reaching any additional goals. There were multiple factors that likely contributed to this outcome, although it remains unclear the extent to which each factor was operating. These possibly include: (a) a mismatch between Charles' preferred treatment (long-term, supportive) and received treatment (short-term, trauma-focused); (b) Charles perceiving cultural insensitivity on my part and/or on the part of the treatments; (c) Charles possibly having had PTSD symptoms so chronic that he had learned to live with them and the cost of confronting the memory of the suicide was not worth it; and/or (d) Charles possibly having had undiagnosed psychopathology (e.g., unspecified personality disorder) that got in the way of him relating to me. In addition, his careless completion of the self-report measures is a problem that occasionally occurs in working with some Veterans. It speaks to the need to triangulate sources of data (e.g., the CAPS, PCL-5, and behavioral observations).

\section{Discussion of Broader Issues Raised by Alex's, Bruno's, and Charles' Cases}

This study intends to shed light upon some of the key issues that may arise when delivering evidence-based treatments through a stepped-care model with Veterans suffering from PTSD in a real-world clinical setting. The composite case studies of "Alex," "Bruno,” and "Charles" were created in order to elucidate themes that emerged during my work with Veteran clients. My goal has been to make their case studies a "best practice" resource for clinicians working with Veterans who suffer from PTSD, while also demonstrating some of the real clinical challenges that can emerge in therapy. Of course, as Alex, Bruno, and Charles are representative of only three individuals, their cases are not intended to generalize to all Veterans. However, the three cases provide a sense of the heterogeneity among veterans with PTSD.

As these cases illustrate, there can be important benefits of engaging in traumafocused, exposure-based treatments for Veterans suffering from PTSD. However, it is also clear that some Veterans, especially older Veterans (e.g., Vietnam-era), may view their illness as chronic and may not be amenable to engaging in these treatments. Based on the research to date (i.e., Sloan et al., 2013) and as illustrated in the three cases, Veterans tolerate Written Exposure Therapy (WET) well and are satisfied with the treatment. It also appears to function nicely as the initial option in a stepped-care model of PTSD treatment. This may be an especially feasible treatment for Returning Veterans, whose lives are often so busy that they prefer not to commit to a longer, more intensive treatment. By providing all Veterans with this treatment at first, it may be possible to allocate resources more effectively because of its cost effectiveness relative to Prolonged Exposure and Cognitive Processing Therapy. Some Veterans, like Alex, will presumably receive enough benefit that they decide not to step-up to an intensive, empirically based treatment like Pronlonged Exposure (PE) or Cognitive Processing Therapy (CPT).

Furthermore, other Veterans, like Bruno, may not have been ready for PE or CPT initially and may have dropped out had they not received WET first. Thus, this model may be especially appealing to large health care systems like the Veterans Health Administration, where patient- centered care and resource management are both priorities. 


\section{REFERENCES}

American Psychiatric Association. (2013). Diagnostic and statistical manual of mental disorders (5th ed.). Arlington, VA: American Psychiatric Publishing.

Austern (2015). Written exposure therapy as step one in reducing the burden of PTSD. Unpublished doctoral dissertation, Rutgers University, Piscataway, NJ. Available at: https://rucore.libraries.rutgers.edu/rutgers-lib/48166/

Barry, M. J., \& Edgman-Levitan, S. (2012). Shared decision making-the pinnacle of patient centered care. New England Journal of Medicine, 366(9), 780-781.

Beck, A. T., Steer, R. A., \& Brown, G. K. (1996). Manual for the beck depression inventory-II.

Bower, P., \& Gilbody, S. (2005). Stepped care in psychological therapies: access, effectiveness and efficiency Narrative literature review. The British Journal of Psychiatry, 186(1), 1117.

Bradley, R., Greene, J., Russ, E., Dutra, L., \& Westen, D. (2005). A multidimensional meta analysis of psychotherapy for PTSD. American Journal of Psychiatry, 162(2), 214-227.

Cigrang, J. A., Rauch, S. A., Avila, L. L., Bryan, C. J., Goodie, J. L., Hryshko-Mullen, A., \& Peterson, A. L. (2011). Treatment of active-duty military with PTSD in primary care: Early findings. Psychological Services, 8(2), 104-113.

Difede, J., Cukor, J., Jayasinghe, N., Patt, I., Jedel, S., Spielman, L., ... \& Hoffman, H. G. (2007). Virtual reality exposure therapy for the treatment of posttraumatic stress disorder following September 11, 2001. Journal of Clinical Psychiatry, 68(11), 1639-1647.

Difede, J., Cukor, J., Wyka, K., Olden, M., Hoffman, H., Lee, F. S., \& Altemus, M. (2014). D cycloserine augmentation of exposure therapy for post-traumatic stress disorder: A pilot randomized clinical trial. Neuropsychopharmacology, 39(5), 1052-1058.

Fishman, D. B. (2013). The Pragmatic Case Study Method for creating rigorous and systematic, practitioner-friendly research. Pragmatic Case Studies in Psychotherapy, 9(4), Article 2, 403-425. Available: http://pcsp.libraries.rutgers.edu, doi: http://dx.doi.org/10.14713/pcsp.v9i4.1833

Foa, E. B. (2009). Effective treatments for PTSD: Practice guidelines from the International Society for Traumatic Stress Studies. Guilford Publication.

Foa, E., Hembree, E., \& Rothbaum, B. O. (2007). Prolonged exposure therapy for PTSD: Emotional processing of traumatic experiences therapist guide. Oxford University Press, USA.

Hamblen, J. L., Bernardy, N. C., Sherrieb, K., Norris, F. H., Cook, J. M., Louis, C. A., \& Schnurr, P. P. (2015, January 19). VA PTSD Clinic Director perspectives: How perceptions of readiness influence delivery of evidence-based PTSD treatment. Professional Psychology: Research and Practice. Advanced online public publication. Http://dx.doi.org/10.1037/a0038535

Hembree, E. A., Foa, E. B., Dorfan, N. M., Street, G. P., Kowalski, J., \& Tu, X. (2003). Do patients drop out prematurely from exposure therapy for PTSD? Journal of Traumatic Stress, 16(6), 555-562.

Imel, Z.E., Laska, K., Jakupcak, M., \& Simpson, T.L. (2013). Meta-analysis of dropout in treatments for posttraumatic stress disorder. Journal of Consulting and Clinical Psychology, 81(3), 394-404. 
Institute of Medicine. (2001). Crossing the quality chasm: A new health system for the $21^{\text {st }}$ century. Washington, DC: National Academy Press.

Jeffreys, M. D., Reinfeld, C., Nair, P. V., Garcia, H. A., Mata-Galan, E., \& Rentz, T. O. (2014). Evaluating treatment of posttraumatic stress disorder with cognitive processing therapy and prolonged exposure therapy in a VHA specialty clinic. Journal of anxiety disorders, 28(1), 108-114.

Kazdin, A. E., \& Blase, S. (2011). Rebooting psychotherapy research and practice to reduce the burden of mental illness. Perspectives on Psychological Science, 6, 21-37.

Kessler, R. C. (2000). Posttraumatic stress disorder: the burden to the individual and to society. Journal of Clinical Psychiatry, 61(5), 4-14.

Kross, E., \& Ayduk, O. (2011). Making meaning out of negative experiences by self-distancing. Current Directions in Psychological Science, 20(3), 187-191.

Larsen, D. L., Attkisson, C. C., Hargreaves, W. A., \& Nguyen, T. D. (1979). Assessment of client/patient satisfaction: development of a general scale. Evaluation and program planning, 2(3), 197-207.

McDonagh, A., Friedman, M., McHugo, G., Ford, J., Sengupta, A., Mueser, K. ... \& Descamps,M. (2005). Randomized trial of cognitive-behavioral therapy for chronic posttraumatic stress disorder in adult female survivors of childhood sexual abuse. Journal of Consulting and Clinical Psychology, 73(3), 515.

Morris, D. (2015, January 17). After PTSD, more trauma. The New York Times, p. SR1.

Mott, J. M., Stanley, M. A., Street Jr, R. L., Grady, R. H., \& Teng, E. J. (2014). Increasing engagement in evidence-based PTSD treatment through shared decision-making: A pilot study. Military Medicine, 179(2), 143-149.

Mott, J. M., Sutherland, R. J., Williams, W., Lanier, S. H., Ready, D. J., \& Teng, E. J. (2013). Patient perspectives on the effectiveness and tolerability of group-based exposure therapy for posttraumatic stress disorder: Preliminary self-report findings from 20 veterans. Psychological Trauma: Theory, Research, Practice, and Policy, 5(5), 453.

Neuner, F., Schauer, M., Klaschik, C., Karunakara, U., \& Elbert, T. (2004). A comparison of narrative exposure therapy, supportive counseling, and psychoeducation for treating posttraumatic stress disorder in an African refugee settlement. Journal of Consulting and Clinical Psychology, 72(4), 579.

Nguyen, T. D., Attkisson, C. C., \& Stegner, B. L. (1983). Assessment of patient satisfaction: Development and refinement of a service evaluation questionnaire. Evaluation and Program Planning, 6(3), 299-313.

Pennebaker, J.W. (2010). Expressive writing in a clinical setting. The Independent Practitioner, 30, 23-25.

Pennebaker, J. W., \& Chung, C. K. (2011). Expressive writing and its links to mental and physical health. In H. S. Friedman (Ed.), Oxford handbook of health psychology. New York, NY: Oxford University Press.

Pennebaker, J. W, Kiecolt-Glaser, J. K., \& Glaser, R. (1988). Disclosure of traumas and immune function: Health implications for psychotherapy. Journal of Consulting and Clinical Psychology, 56, 239-245.

Peterson, D.R. (1996). Making psychology indispensable. Applied \& Preventive Psychology, 5,1-8. 
Resick, P.A., Monson, C.M., \& Rizvi, S.L. (2008). Posttraumatic Stress Disorder, in D.H. Barlow (Ed.)., Clinical handbook of psychological disorders: A step-by-step treatment manual, $4^{\text {th }}$ ed., 654-122 New York, Guilford.

Resick, P. A., Nishith, P., Weaver, T. L., Astin, M. C., \& Feuer, C. A. (2002). A comparison of cognitive-processing therapy with prolonged exposure and a waiting condition for the treatment of chronic posttraumatic stress disorder in female rape victims. Journal of Consulting and Clinical Psychology, 70(4), 867.

Resick, P. A., \& Schnicke, M. K. (1992). Cognitive processing therapy for sexual assault victims. Journal of Consulting and Clinical Psychology, 60(5), 748.

Schell, T. L., \& Marshall, G. N. (2008). Survey of individuals previously deployed for OEF/OIF. In T.L. Tanielian \& L.H. Jaycox (Eds.). Invisible wounds of war: Psychological and cognitive injuries, their consequences, and services to assist recovery, 87-115. Santa monica, CA: RAND Corporation.

Schottenbauer, M. A., Glass, C. R., Arnkoff, D. B., \& Gray, S. H. (2008). Contributions of psychodynamic approaches to treatment of PTSD and trauma: A review of the empirical treatment and psychopathology literature. Psychiatry, 71(1), 13-34.

Sloan, D. M., Marx, B. P., \& Resick, P. A. (2016). Brief treatment for PTSD: A non-inferiority trial. Contemporary Clinical Trials, 48, 76-82.

Sloan, D.M., Lee, D.J., Litwack, S.D., Sawyer, A.T., \& Marx, B.P. (2013). Written exposure therapy for veterans diagnosed with PTSD: A pilot study. Journal of Traumatic Stress, 26(6), 776-9.

Sloan, D. M., Marx, B. P., Bovin, M. J., Feinstein, B. A., \& Gallagher, M. W. (2012). Written exposure as an intervention for PTSD: A randomized clinical trial with motor vehicle accident survivors. Behaviour Research and Therapy, 50(10), 627-635.

Sloan, D.M., Marx, B.P., \& Greenberg, E.M. (2011). A test of written emotional disclosure as an intervention for posttraumatic stress disorder. Behaviour Research and Therapy, 49,299304.

Sloan, D.M., Marx, B.P., \& Keane, T.M. (2011). Reducing the burden of mental illness in military veterans: Commentary on Kazdin and Blase (2011). Perspectives on Psychological Science, 6, 503-506.

Sprinkle S.D., Lurie D., Insko S.L., Atkinson G., Jones G.L., Logan A.R., \& Bissada N.N. (2002). Criterion validity, severity cut scores, and test-retest reliability of the Beck Depression Inventory-II in a university counseling center sample. Journal of Counseling Psychology, 49, 381-385.

Tanielian, T. L., Jaycox, L. H., Schell, T. L., Marshall, G. N., Burnam, M. A., Eibner, C., ... \& Vaiana, M. E. (2008). Invisible wounds of war: Summary and recommendations for addressing psychological and cognitive injuries, 431-453. Santa Monica, CA: RAND Corporation.

Tuerk, P. W., Wangelin, B., Rauch, S. A., Dismuke, C. E., Yoder, M., Myrick, H., ... \& Acierno, R. (2013). Health service utilization before and after evidence-based treatment for PTSD. Psychological Services, 10, 401-409.

Weathers, F. W., Blake, D. D., Schnurr, P. P., Kaloupek, D. G., Marx, B. P., \& Keane, T. M. (2013). The Clinician-Administered PTSD Scale for DSM-5 (CAPS-5). Scale available from the National Center for PTSD. 
Weathers, F.W., Blake, D.D., Schnurr, P.P., Kaloupek, D.G., Marx, B.P., \& Keane, T.M. (2013). The Life Events Checklist for DSM-5 (LEC-5). Scale available from the National Center for PTSD. .

Weathers, F. W., Litz, B. T., Keane, T. M., Palmieri, P. A., Marx, B. P., \& Schnurr, P. P. (2013). The PTSD Checklist for DSM-5 (PCL-5). Scale available from the National Center for PTSD.

See:http://www.ptsd.va.gov/professional/assessment/adult-sr/ptsd-checklist.asp

Wortmann, J. H., Jordan, A. H., Weathers, F. W., Resick, P. A., Dondanville, K. A., Hall-Clark, B., \& ... Litz, B. T. (2016). Psychometric analysis of the PTSD Checklist- 5 (PCL-5) among treatment-seeking military service members. Psychological Assessment, 28, 13921403. doi:10.1037/pas0000260

Yoder, M., Tuerk, P. W., Price, M., Grubaugh, A. L., Strachan, M., Myrick, H., \& Acierno, R. (2012). Prolonged exposure therapy for combat-related posttraumatic stress disorder: Comparing outcomes for veterans of different wars. Psychological services, 9, 16. 
Table 1

Alex’s, Bruno’s, and Charles’ Scores: PTSD Checklist for DSM-5

\begin{tabular}{|c|c|c|c|}
\hline Session Number (Session Content) & Alex & Bruno & Charles \\
\hline 1 (Assessment \& Treatment Planning) & $60^{\mathrm{a}}$ & 72 & 48 \\
\hline 2 (Written Exposure Therapy Session 1) & 62 & 71 & 42 \\
\hline 3 (Written Exposure Therapy Session 2) & 58 & 76 & 50 \\
\hline 4 (Written Exposure Therapy Session 3) & 63 & 68 & 39 \\
\hline 5 (Written Exposure Therapy Session 4) & 54 & 61 & 46 \\
\hline 6 (Written Exposure Therapy Session 5) & 46 & 57 & 45 \\
\hline 7 (Treatment Planning) & $40^{*}$ & 54 & 37 \\
\hline 8 (Prolonged Exposure Session 1) & & 55 & 40 \\
\hline 9 (Prolonged Exposure Session 2) & & 56 & 45 \\
\hline 10 (Prolonged Exposure Session 3) & & 53 & \\
\hline 11 (Prolonged Exposure Session 4) & & 59 & \\
\hline 12 (Prolonged Exposure Session 5) & & 52 & \\
\hline 13 (Prolonged Exposure Session 6) & & 47 & \\
\hline 14 (Prolonged Exposure Session 7) & & 36 & \\
\hline 15 (Prolonged Exposure Session 8) & & 42 \\
\hline 16 (Prolonged Exposure Session 9) & & \\
\hline
\end{tabular}

${ }^{\text {a }}$ A score of 38 has been suggested as a cutoff for probable PTSD, thus scores above 38 reflect the likely presence of PTSD. As clinical norms are being developed for the PCL-5, it is expected that score reductions of 5-10 points represents reliable change and score reductions of 10-20 points represents clinically meaningful change.

* Denotes statistically reliable and clinically meaningful change. 
Table 2

$\underline{\text { Alex’s, Bruno’s, and Charles’ Scores: Beck Depression Inventory-Second Version }^{\text {a }}}$

\begin{tabular}{|c|c|c|c|}
\hline Session Number (Session Content) & Alex & Bruno & Charles \\
\hline 1 (Assessment \& Treatment Planning) & 18 & 21 & 16 \\
\hline 2 (Written Exposure Therapy Session 1) & 20 & 24 & 11 \\
\hline 3 (Written Exposure Therapy Session 2) & 21 & 26 & 17 \\
\hline 4 (Written Exposure Therapy Session 3) & 17 & 22 & 23 \\
\hline 5 (Written Exposure Therapy Session 4) & 15 & 20 & 14 \\
\hline 6 (Written Exposure Therapy Session 5) & 13 & 19 & 19 \\
\hline 7 (Treatment Planning) & $12^{*}$ & 18 & 15 \\
\hline 8 (Prolonged Exposure Session 1) & & 17 & 16 \\
\hline 9 (Prolonged Exposure Session 2) & & 18 & 18 \\
\hline 10 (Prolonged Exposure Session 3) & & 23 & \\
\hline 11 (Prolonged Exposure Session 4) & & 24 & \\
\hline 12 (Prolonged Exposure Session 5) & & 21 & \\
\hline 13 (Prolonged Exposure Session 6) & & 24 & \\
\hline 14 (Prolonged Exposure Session 7) & & $14^{*}$ & \\
\hline 15 (Prolonged Exposure Session 8) & & 23 & \\
\hline 16 (Prolonged Exposure Session 9) & & & \\
\hline
\end{tabular}

a Scores range from 0-63, where 0-13 is indicative of minimal depression; 14-19 suggests mild and 29-63 reflects severe depression 20-28 implies moderate depression; and 29-63 reflects severe depression. Score categorization as noted by Beck, Steer, and Brown (1996) in the Manual for the Beck Depression Inventory-II.

* Denotes reliable change because BDI-II score reductions of 6 and 7 points respectively exceed the RCI of 5.78 (95\% confidence; Sprinkle et al., 2002) 
Table 3

Bruno's In Vivo Exposure Hierarchy ${ }^{\text {a }}$

\begin{tabular}{|c|c|c|c|}
\hline & Item & $\begin{array}{l}\text { SUDS } \\
\text { (beginning) }\end{array}$ & $\begin{array}{l}\text { SUDS } \\
\text { (end) }\end{array}$ \\
\hline 1 & $\begin{array}{l}\text { Sitting in the lobby of the state VA hospital at a non-busy time for } 30 \\
\text { minutes }\end{array}$ & 40 & 0 \\
\hline 2 & Calling his daughters and talking for 30 minutes & 40 & 0 \\
\hline 3 & Cooking a meal for the halfway house residents and eating with them & 45 & 0 \\
\hline 4 & Going on a date with a woman from Okcupid & 45 & 15 \\
\hline 5 & $\begin{array}{l}\text { Going to Walmart during a non-busy time and standing in the } \\
\text { sporting goods section for } 45 \text { minutes }\end{array}$ & 50 & 0 \\
\hline 6 & Going to the YMCA and working out for 30 minutes & 55 & 5 \\
\hline 7 & Riding the bus during rush hour for 45 minutes & 60 & 5 \\
\hline 8 & $\begin{array}{l}\text { Seeing an action movie on opening night and sitting in the middle of } \\
\text { the theater }\end{array}$ & 65 & 5 \\
\hline 9 & $\begin{array}{l}\text { Riding the elevator at the state VA hospital at a busy time for } 45 \\
\text { minutes }\end{array}$ & 70 & 10 \\
\hline 10 & $\begin{array}{l}\text { Standing at the bar with my back to the crowd on college night for } 60 \\
\text { minutes }\end{array}$ & 75 & 15 \\
\hline 11 & $\begin{array}{l}\text { Taking a shower in the halfway house shared bathroom with the door } \\
\text { unlocked for } 30 \text { minutes }\end{array}$ & 80 & 40 \\
\hline 12 & $\begin{array}{l}\text { Watch the "squeal like a pig" scene from Deliverance on repeat for } \\
30 \text { minutes }\end{array}$ & 85 & 50 \\
\hline 13 & Volunteer to staff the phone hotline for my local rape crisis center & 85 & 25 \\
\hline 14 & $\begin{array}{l}\text { Letting a large man "spot me" while I'm doing bench presses at the } \\
Y M C A\end{array}$ & 90 & 40 \\
\hline 15 & $\begin{array}{l}\text { Taking a shower in the halfway house shared bathroom with the } \\
\text { lights off and door unlocked for } 30 \text { minutes }\end{array}$ & 95 & 60 \\
\hline 16 & Taking a shower at the YMCA naked for 30 minutes & 100 & 75 \\
\hline
\end{tabular}

aAnchor Points for SUDS scale: 0 = "being back in my childhood home helping my grandmother cook," 25 = "public speaking class senior year of High School," 50 = "the flight to boot camp when I was really nervous," 75 = "when a large man approaches me now," 100 = "the rape" 
Table 4

Diagnosis at Beginning and End of Treatment

\begin{tabular}{|c|c|c|c|c|}
\hline \multirow{2}{*}{$\begin{array}{l}\text { Veteran } \\
\text { Alex }\end{array}$} & \multicolumn{2}{|c|}{$\begin{array}{l}\text { DSM-5 Diagnosis at Beginning of } \\
\text { Therapy }\end{array}$} & \multicolumn{2}{|c|}{ DSM-5 Diagnosis at End of Therapy } \\
\hline & 309.81 & Posttraumatic Stress Disorder & 309.81 & Posttraumatic Stress Disorder \\
\hline & V719.46 & Knee Joint Pain & V719.46 & Knee Joint Pain \\
\hline Bruno & $\begin{array}{l}309.81 \\
303.90\end{array}$ & $\begin{array}{l}\text { Posttraumatic Stress Disorder } \\
\text { Alcohol Use Disorder, in early } \\
\text { remission, in a controlled } \\
\text { environment }\end{array}$ & 303.90 & $\begin{array}{l}\text { Alcohol Use Disorder, in early } \\
\text { remission, in a controlled } \\
\text { environment }\end{array}$ \\
\hline Charles & 309.81 & Posttraumatic Stress Disorder & 309.81 & Posttraumatic Stress Disorder \\
\hline
\end{tabular}

$\underline{\text { Table } 5}$

Alex’s, Bruno's, and Charles’ Scores: CSQ $^{\text {a }}$

\begin{tabular}{|c|c|c|c|}
\hline Session Number (Session Content) & Alex & Bruno & Charles \\
\hline 7 (Treatment Planning) & 29 & 30 & 31 \\
\hline
\end{tabular}

\footnotetext{
${ }^{\mathrm{a}}$ Higher scores suggest higher levels of satisfaction. 32 is the maximum score.
} 